\title{
Projected Climate Change and Impact on Bioclimatic Conditions in Central and South-Central Asia ICRAF East and Central Asia Research Report
}

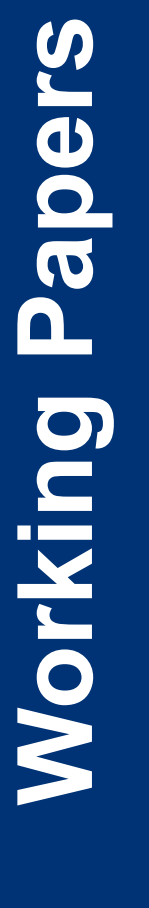

Dr Robert J. Zomer, Mingcheng Wang, Dr Jianchu Xu

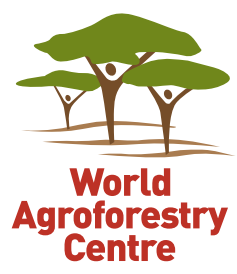




\section{Projected Climate Change and Impact on Bioclimatic Conditions in Central and South-Central Asia}

ICRAF East and Central Asia Research Report

Dr Robert J. Zomer, Mingcheng Wang, Dr Jianchu Xu

Working Paper 187 


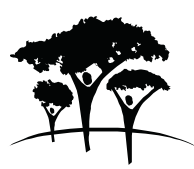

World Agroforestry Centre

TRANSFORMING LIVES AND LANDSCAPES

\section{Correct citation:}

Zomer, R.J.; Wang, M.; and Xu, J., 2015. Projected climate change and impact on bioclimatic conditions in Central and South-Central Asia. ICRAF Working Paper 187. World Agroforestry Centre East and Central Asia, Kunming, China. 50 pp.

\section{DOI: $10.5716 / \mathrm{WP} 14144$}

Titles in the Working Paper Series aim to disseminate interim results on agroforestry research and practices and stimulate feedback from the scientific community. Other publication series from the World Agroforestry Centre include: Agroforestry Perspectives, Technical Manuals and Occasional Papers.

Published by the World Agroforestry Centre

East and Central Asia Regional Programme

\% Kunming Institute of Botany, Chinese Academy of Science

3/F North Research Building

Heilongtan, 650201 Kunming

Yunnan Province, P.R. China

Tel.: +86-871-6522-3014 - Fax: +86-871-6522-3377

Email: s.vandemoortel@cgiar.org

Internet: www.worldagroforestry.org/eca

(C) World Agroforestry Centre 2015

Working Paper No. 187

Photos: Evgeni Zotov, Tomas Depenbusch, Charles Roffey, Peretz Partensky, Martine, Oleg Brovko and Dieter Zirnig on Flickr, and Jianchu Xu.

\section{Disclaimer and copyright}

The views expressed in this publication are those of the author(s) and not necessarily those of the World Agroforestry Centre. Articles appearing in this publication may be quoted or reproduced without charge, provided the source is acknowledged. All images remain the sole property of their source and may not be used for any purpose without written permission of the source. 


\section{About the authors}

Prof Dr Robert Zomer is a landscape ecologist, with a broad background in plant community, forest and agricultural ecology, and advanced skills in statistical analysis, geographic information systems (GIS), remote sensing, environmental modelling, and landscape-level spatial analysis. He is currently a visiting Professor at Kunming Institute of Botany and a Senior Landscape Ecologist at the World Agroforestry Centre's East and Central Asia Regional Programme.

Prof Dr Jianchu Xu is an internationally respected leading ethno-ecologist who works in coupled human environmental systems. His current research includes investigation of early warning signals of global change, trans-boundary water governance, landscape restoration, ecosystem services and their resilience, agriculture, and integrative conservation. Dr Xu leads the World Agroforestry Centre's East and Central Asia Regional Programme.

Mr Mingcheng Wang has a geospatial modelling and remote sensing background, with advanced skills in multi-spectral and multi-resolution satellite remote sensing, geographic information systems (GIS), geospatial analysis, spatial analytical programming and map production, and spatial data analysis and statistics. Special interests include the impacts of climate change on hydrological processes, terrestrial ecosystems, biodiversity conservation, farming systems, and the spatial distribution of natural biodiversity, cropping systems and potentially useful agroforestry species.

\section{Acknowledgment}

This synthesis is conducted under the auspices of the World Agroforestry Centre - East and Central Asia Region. Partial support was provided by the CGIAR Research Programmes on Dryland Systems (CRP1.1): Integrated Agricultural Production Systems for the Poor and Vulnerable in Dry Areas. 


\section{Abstract}

This report summarizes the current and future projected status of a set of bioclimatic indicators and the expected impacts of climate change on bioclimatic conditions in central and south-central Asia. It is intended to provide a basis for understanding the potential impacts of climate change across central and south-central Asia and a knowledge base for the design and implementation of agroforestry practices, environmental conservation efforts, and sustainable development.

Under all scenarios, our spatial analysis indicates quick and drastic change in bioclimatic conditions in the near to medium term, and predicts significant and increasing biophysical and biological perturbation for biodiversity, ecosystems and ecosystem services, and agricultural and pastoral production systems.

The major conclusion to be drawn from this report is the overriding necessity to recognize the now central role of a rapidly changing climate and environment across central and south-central Asia, and the need to plan for adaptation within almost all aspects of sustainable development and conservation planning, efforts and policy.

\section{Keywords}

Climate change, South Central Asia, Pakistan, Afghanistan, Tajikistan, Kyrgyzstan, Uzbekistan, Turkmenistan, China, Central Asia, Hydrology

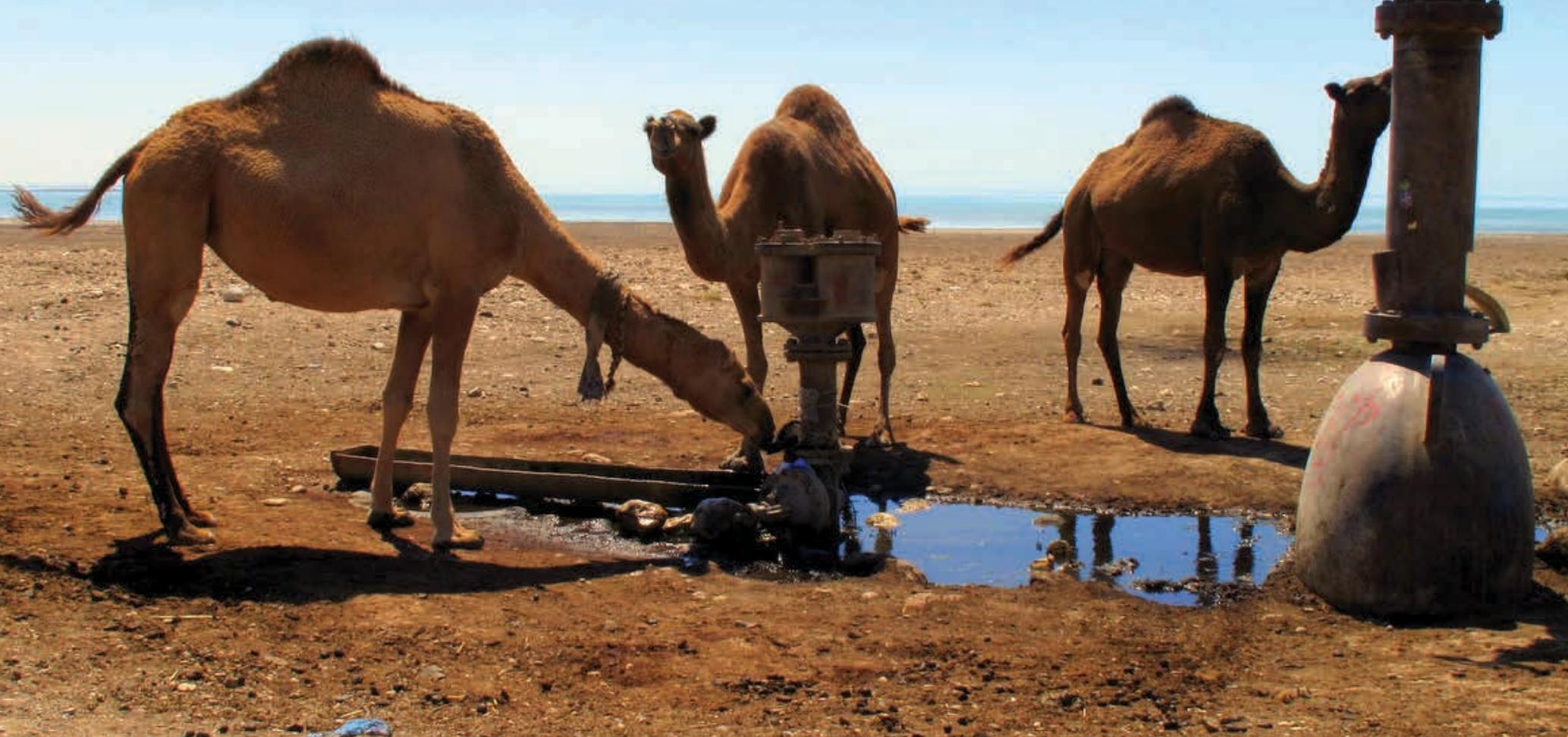




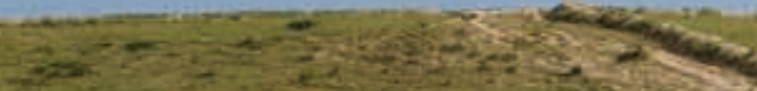

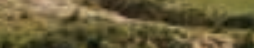

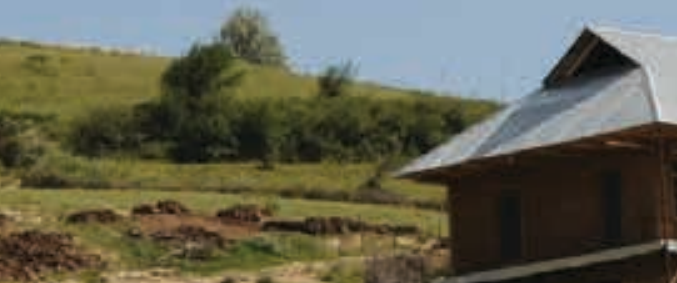

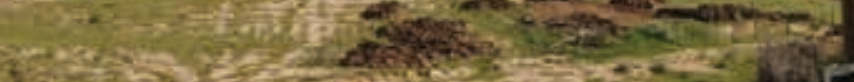

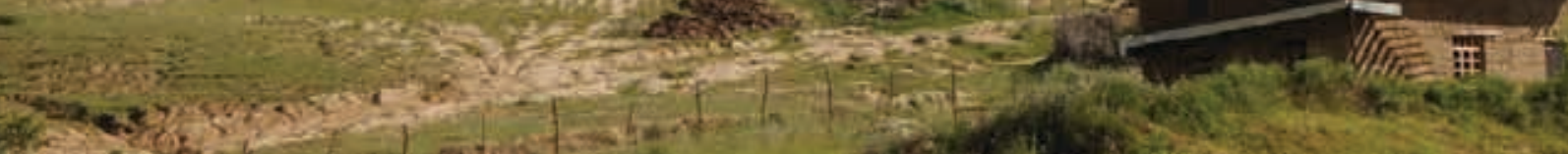

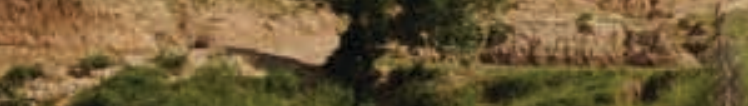
sations

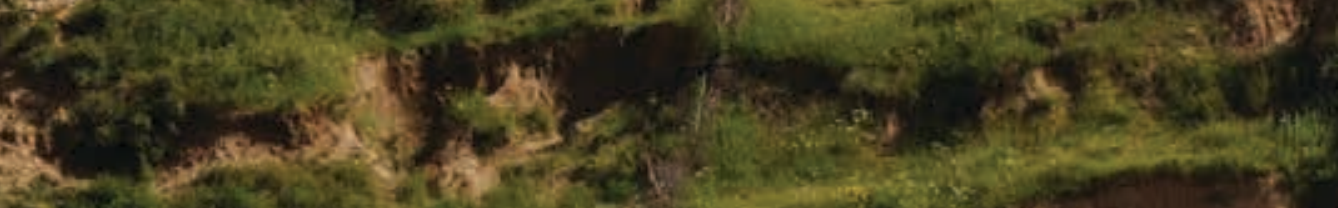

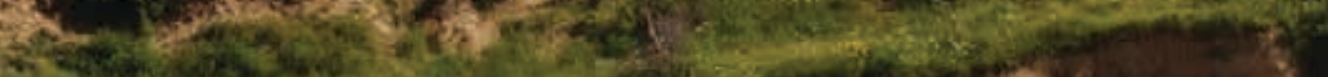

Salow

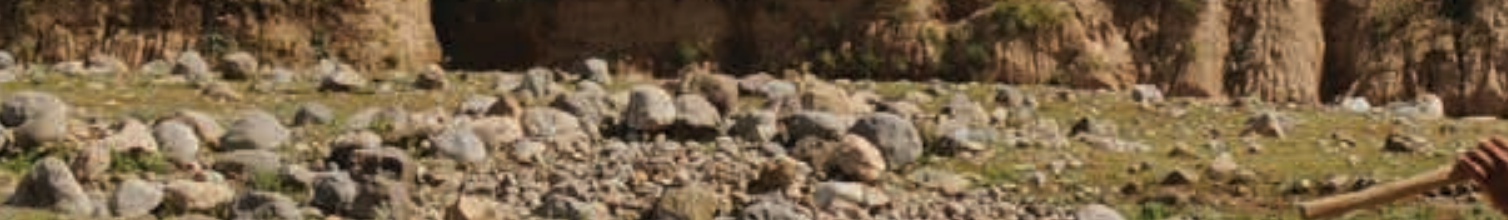

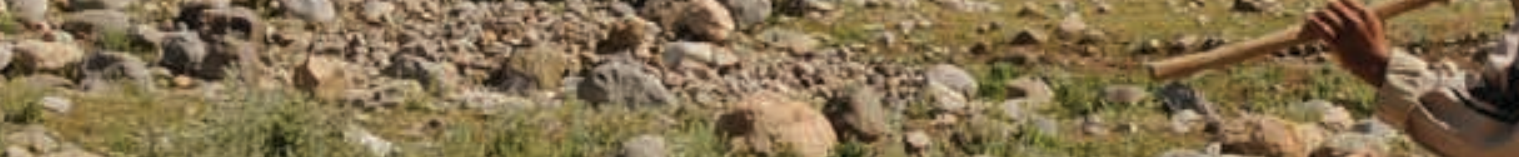

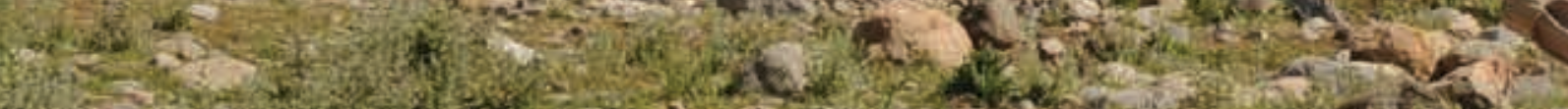

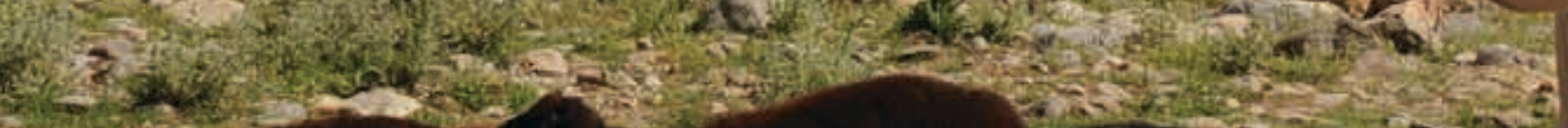

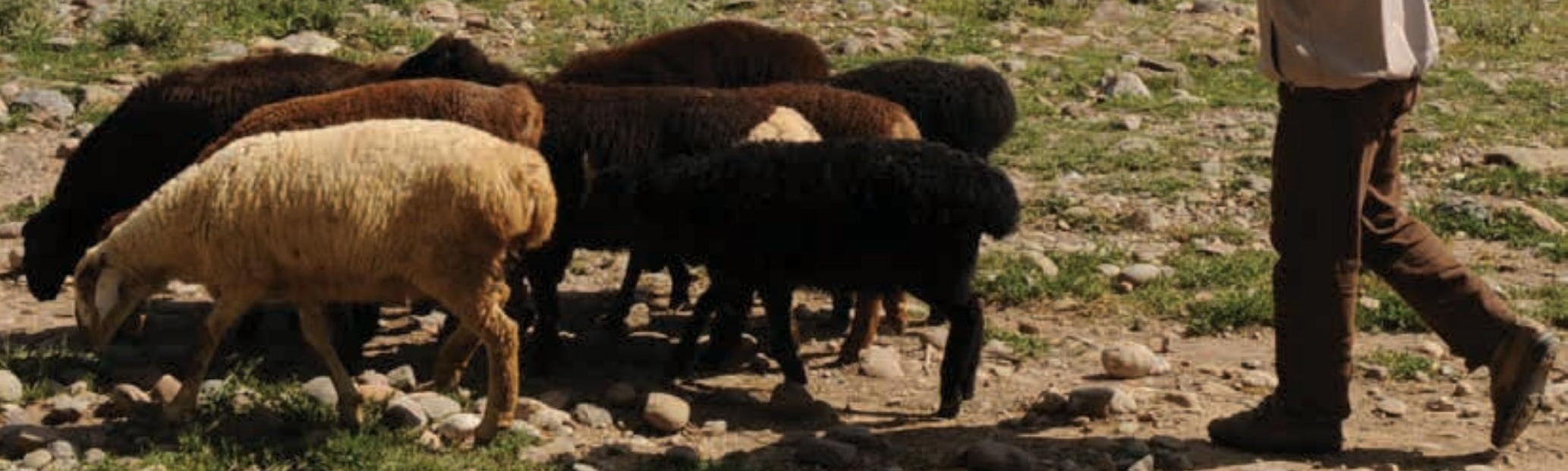

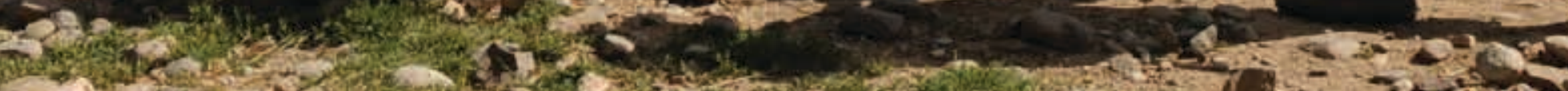

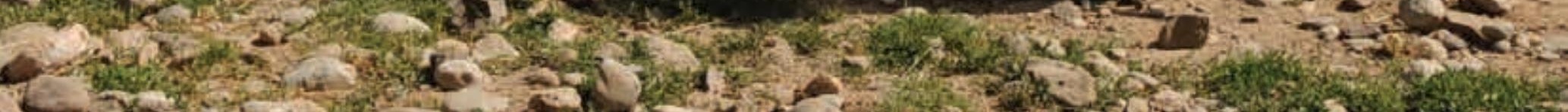




\section{Contents}

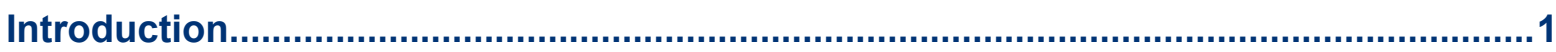

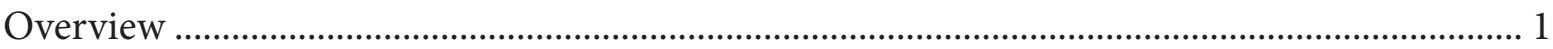

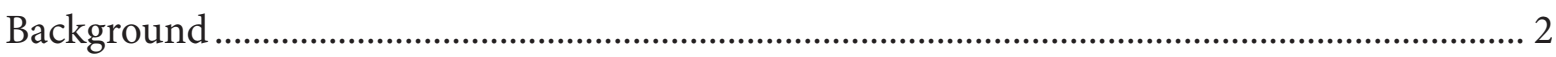

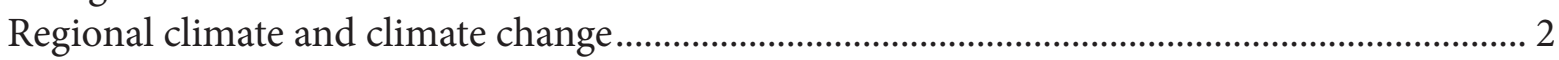

Assumptions, sources of uncertainty, and other limitations ...................................................... 4

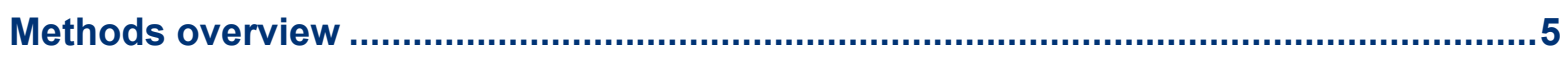

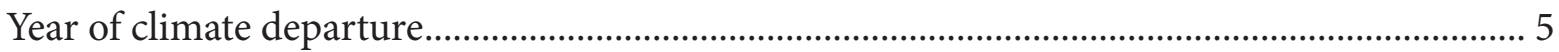

Projected changes in temperature and precipitation .............................................................. 5

Projected changes in potential evapotranspiration and aridity-wetness index........................... 6

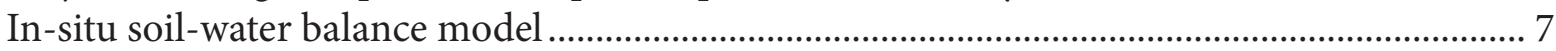

Environmental stratification and delineation of bioclimatic zones ............................................ 7

Modelling of projected future bioclimatic conditions................................................................. 8

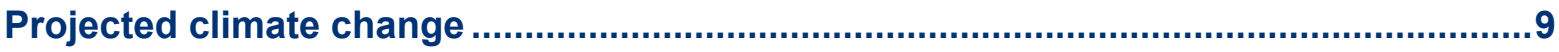

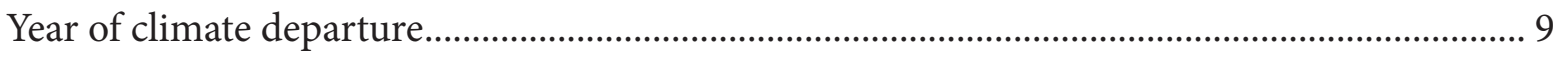

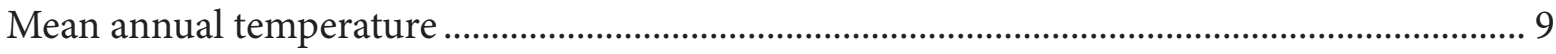

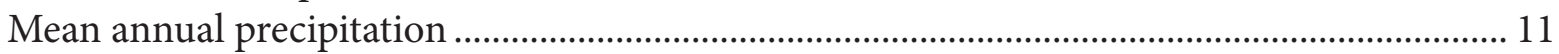

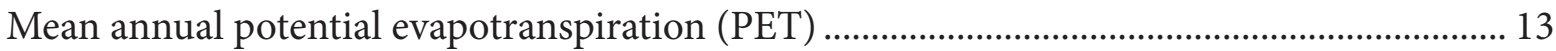

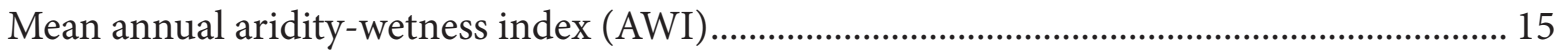

In-situ hydrologic status: soil-water balance model ................................................................ 16

Projected change in spatial distribution of bioclimatic conditions..............................20

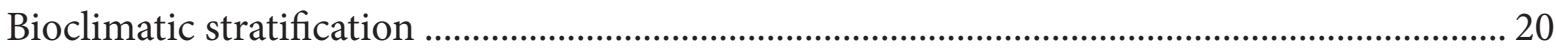

Projected change in spatial distribution of bioclimatic zones .................................................... 22

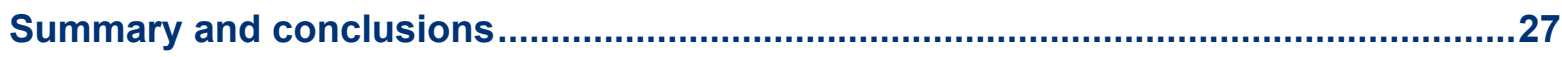

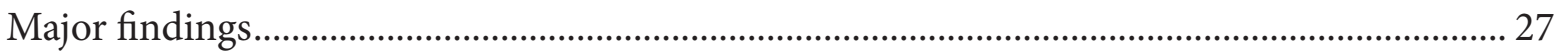

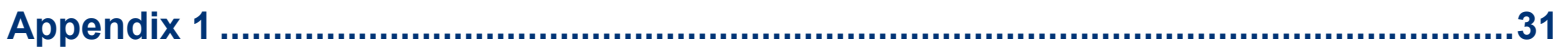

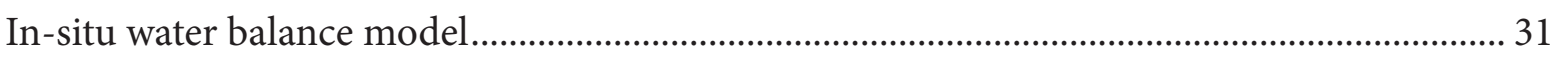

Monthly Potential Evapotranspiration (PET) .......................................................................... 31

Actual Evapotranspiration and Green Water Vapour Flows …................................................ 32

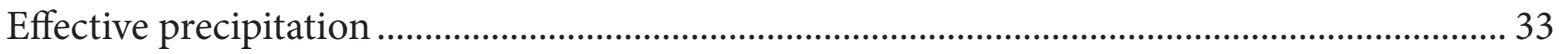

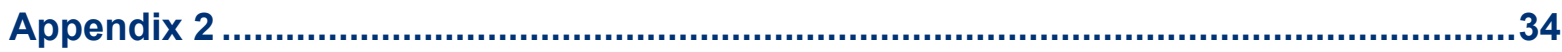

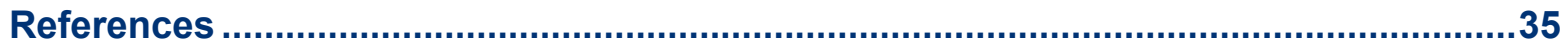




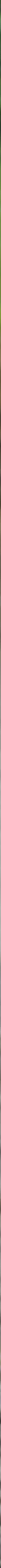




\section{Introduction}

\section{Overview}

In this report, we summarize the current and future projected status of a set of bioclimatic indicators and the expected impacts of climate change on the spatial distribution of bioclimatic conditions within the five central Asian (Kazakhstan, Kyrgyzstan, Tajikistan, Turkmenistan, Uzbekistan) and two south-central Asian countries (Afghanistan and Pakistan). Results and conclusions are presented for the combined region as a whole, and individually by country, based upon a geospatial analysis of spatially interpolated weather station data averaged over 40 years, from 1960 to 2000 (referred to below as "2000" or current conditions), and a downscaled multi-model ensemble of the recent Coupled Inter-Comparison Model Project - Phase 5 (CIMP-5) future climate projections $(n=63)$, across the range of Intergovernmental Panel on Climate Change - Fifth Assessment Report (IPCC AR-5) representative concentration pathways (RCPs), which are four greenhouse gas concentration (not emissions) trajectories adopted by the Intergovernmental Panel on Climate Change (IPCC) for its fifth Assessment.

A modelling approach based on a simple in-situ soil-water balance model, and a statistically derived environmental stratification is used to predict and understand the nature and magnitude of projected changes in the spatial distribution of bioclimatic conditions across central and south-central Asia by the year 2050, based on the multi-model ensemble of downscaled (1-km resolution) CIMP5 Earth System Model projections. This overview and analysis is intended to provide a basis for, and a first step towards, understanding the potential impacts of climate change across central and south-central Asia in the near to medium term (i.e. 2050, represented as a 30-year average of the period 2035 to 2065) on terrestrial ecosystems, biodiversity, agricultural production, and pastoral systems. Both the regional environmental stratification (CA_EnS), and the analysis of projected change in spatial distribution of bioclimatic conditions can provide important inputs and a knowledge base for climate change adaptation planning and policies, and, in particular, for the design and implementation of agroforestry practices, environmental conservation efforts, and sustainable development.

Climate change is and has been on-going, and is already evident and widely observed across the region. Meteorological data series for Central Asia have shown a steady increase of annual and winter temperatures since the beginning of the $20^{\text {th }}$ century. In line with predictions by global climate change models generally, the frequency of droughts has been observed to increase over the last few last decades, highlighting the predicted increase in inter-annual, as well as intra-annual variability and frequency of extreme events.

Overall, the results of our spatial analysis based upon the CIMP-5 Earth System Model projections indicate a fairly quick and drastic change in the spatial distribution of bioclimatic conditions across the central and south-central region, and predict significant and increasing biophysical and biological perturbation for biodiversity, ecosystems and ecosystem services, and agricultural and pastoral production systems, in the near- to medium-term future under all scenarios. The magnitude of predicted change indicated by our analysis points to a prolonged period of profound impacts on terrestrial ecosystems, biodiversity, and ecosystem services across central Asia, well under way by 2050 as a result of warming and climate disruption, and the shifting of bioclimatic conditions spatially, particularly within mountainous terrain. As the century progresses, this change will have increasingly substantial and direct impacts on ecosystems, biodiversity, agricultural crops, pastoral systems, water resources, as well as human health and livelihoods throughout this region. Likewise, effectiveness of conservation efforts will be affected, as ecological conditions across the region may change beyond limits conducive for the species currently found within narrow niches or designated protected areas, or allow for newly invasive species. 
The major conclusion to be drawn from this report is the overriding necessity to recognize the now central role of a rapidly changing climate and environment across the central and south-central Asian region, and the need to plan for adaptation within almost all aspects of sustainable development and conservation planning, efforts and policy.

\section{Background}

Although there are great uncertainties in our understanding of future climate and climate change, it is generally recognized that central Asia and south-central Asia, like other ecologically arid and/ or semi-arid regions of the world, and like other economically less-developed countries, are likely to be highly vulnerable to future anticipated climatic change and associated ecological perturbations (Lioubimtseva and Henebry, 2009; Pilifosova et al, 1997). Improving our understanding of the nature of these changes in bioclimatic conditions, both in the near to medium term, as this study focuses on (i.e. 2050), and/or in the longer term (i.e. by the end of the century), is essential to provide the knowledge base and allow for science/evidenced-based decision-making for adaptation and sustainable environmental planning. Regional vulnerability and adaptation to changing climatic conditions include both biophysical and socio-economic dimensions, with climate change being one of many factors within a complex matrix of on-going change processes, including globalization, market integration, and regional socio-economic and cultural change. Nevertheless, climate change will have increasingly substantial and direct impacts on ecosystems, biodiversity, agricultural crops, pastoral systems, water resources, as well as human health and livelihoods, throughout this region as this century progresses.

The physical geography of central and south-central Asia, dominated by deserts and semi-deserts with scarce water resources, in addition to a legacy of central planning and historical reliance on monocultural agricultural production for export, the recent post-Soviet economic collapse and upheaval, and a state of relative under-development, leaves this region particularly vulnerable to climateinduced disruption. More specifically, the low levels of precipitation which are the norm across the region mean that ecological and agricultural systems may already be water-stressed or heavily reliant on groundwater or other non-sustainable irrigation sources, close to minimum thresholds, and/or face other related issues such as desertification, salinization, and/or land degradation.

Geographic regions and socio-economic groups that are already vulnerable to contemporary climate variability and extreme weather events are very likely to become more vulnerable in the future. However, a long historical experience of indigenous ecological knowledge, adaptive strategies and coping skills, developed within the context of, and specifically in response to highly variable precipitation and other bioclimatic conditions provides the basis for adaptation strategies and local responses. Likewise, high levels of local and indigenous agro-biodiversity, particularly fruit and nut trees, and local livestock landraces, provide important genetic resources for future adaptive responses and provide economic opportunities which may result from changed bioclimatic conditions.

\section{Regional climate and climate change}

Both central Asia and south-central Asia have a generally arid and semi-arid continental climate. Hot, cloudless, dry summers, and with relatively warm, moist winters in the south and cold winters with severe frost in the north, are typical of central Asia. Key features of central Asia's climate are a pronounced degree of aridity and large seasonal temperature fluctuations, typical of continental climates un-buffered by oceanic influences, and including a constant moisture deficit and low relative humidity. High mountains in the southeast and east of central Asia act as a massive barrier between cold northern Eurasian airflows, and warm southern ones primarily from the Indian Ocean. The warmer, humid oceanic airflows coming from the oceans to the south are blocked by these formidable 
mountain ranges of the Hindu Kush and western Himalaya, creating a massive rain-shadow effect covering all of central Asia. Within this general context, however, there is substantial variability and variation in climatic regimes throughout most of the region.

Most existing literature on climate and environmental change in central Asia is in Russian (Lioubimtseva et al, 2005) and, consequently, generally outside the purview of the international community, although more recently this has begun to change. However, the importance of climate variability in central Asia has been an important topic to Russian-speaking scholars for some time. For example, the decline of the classical and medieval civilization of Turkistan has been attributed to an increase in aridity, although this hypothesis has been rejected by other researchers, who claim that the climatic and environmental changes seen in central Asia over the last millennia have been caused by human activities. The question posed more than 60 years ago, "is central Asia getting drier?" (Markov, 1951), still remains pertinent today, and unresolved. Likewise, the question of climatic change versus human-induced environmental change continues to be debated and strongly interlaced and interdependent within the region, for example, local land use changes, such as massive irrigation, overgrazing and consequent desertification processes are evident.

Although there has been significant progress and a growing understanding of global climate change, a substantial level of uncertainty still exists in the prediction of responses, particularly within arid regions, to global and regional natural, and human-induced climate change. Nevertheless, climate change is already evident in the region. Since the beginning of the $20^{\text {th }}$ century, meteorological data series for central Asia indicate a steady increase of annual and winter temperatures (Conrad et al, 2012; Lioubimtseva et al, 2005). Similarly, the frequency of droughts has reportedly increased over the last few last decades, particularly in Kazakhstan, Turkmenistan and Uzbekistan (Dukhovny and Ziganshina, 2011), i.e. the downstream and more water dependent countries. Severe droughts in the region in 2000-2001 reduced incomes of rural population, with a recovery period of five years for household economies to return to normal levels (Dukhovny and Ziganshina, 2011).

An overview of projected trends for anticipated and modelled climate change across the central Asia region, as published to date (mostly based on IPCC Fourth Assessment Report (AR4) - Special Report on Emissions Scenarios (SRES) scenarios), generally indicate that the magnitude of these affects will impact substantially upon land cover, land use, and agricultural production, with an expected increase in temperature, averaged across the region, of approx. $1-2^{\circ} \mathrm{C}$ by $2030-2050$ (Lioubimtseva et al, 2005). For example, these projected effects of climate change, particularly if they include reduced precipitation or increased water scarcity due to increased potential evapotranspiration, could affect crop yields and natural pastures, and impact food security and rural incomes (Bobojonov and AwHassan, 2014). Particularly relevant for the area, it has been estimated that with only $1^{\circ} \mathrm{C}$ increase in temperature, the demand for agricultural irrigation in the arid and semi-arid regions of central Asia is estimated to increase by at least $10 \%$, due to increased potential evapotranspiration (Fischer et al, 2007). Perelet (2007) estimates that the availability of water in the two main rivers of central Asia the Amu Darya and Syr Darya - will be reduced due to climate change impacts, which potentially will impact on both food security and the maintenance of environmental flows within these rivers and their tributaries.

There are significant implications of these projected levels of climatic change which will drive spatial redistribution and shifting of bioclimatic conditions across the region, and impact on terrestrial ecosystems, vegetation types, wildlife habitat, growing conditions, and agricultural and pastoral production systems (Zomer et al, 2014). For example, the lower limit of fir trees in the Tien Shan is reported to have shifted 100 to 200 meters upslope (Alibekov, 2000). These areas, formerly mountain forests, are now being replaced by sedge-meadow grass formations. Other factors, such as cutting and/ or grazing of animals may also have contributed to this change. 


\section{Assumptions, sources of uncertainty, and other limitations}

Water availability for human activities and maintaining a healthy terrestrial and aquatic ecosystem function is dramatically more important in arid regions such as central and south-central Asia, where there are strong competing demands, including for maintaining natural ecosystems and biodiversity. As such, understanding the hydrological implications of climate change becomes a crucial element of the knowledge required for planning and implementing science-based adaptation strategies and sustainable national development policies. Unfortunately, the ranges of the precipitation projections are still quite uncertain for central Asia, as well as for many other regions in the world, and particularly so in the mountainous region of Asia and elsewhere. Given the low absolute amounts of precipitation and high inter-annual, seasonal, and spatial variability of precipitation across the region already, earlier IPCC AR4 predictions have been deemed not to be reliable (Lioubimtseva, 2007). For smallscale farming, rain-fed agriculture, pastoral systems, and the assessment of human vulnerability, and to some extent of natural ecosystems as well, the changes in the spatial and temporal distribution of precipitation, and inter- and intra-annual variability, maybe more relevant than absolute precipitation values (Lioubimtseva and Henebry, 2009). However, these important dimensions of year to year variability and the intra-annual nuances of climate change are also more difficult to model and project.

In this paper, we report the mean annual results for a set of bioclimatic indicators which includes the basic climatic parameters of mean annual temperature, precipitation, potential evapotranspiration, and an aridity-wetness index. In-situ soil water balance modelling is done on a monthly basis, and provides a simple overview of the hydrological status of a spatially referenced and delineated area, dividing the input of precipitation into three compartments, namely 1) vapour flow or actual evapotranspiration (AET), 2) soil water content (SWC), and excess in-situ water or runoff (ROF). It does not account for overland flow or ground water inputs, and as such is most relevant to rainfed agricultural, pastoral and natural ecosystems. In order to account for the variability amongst the various ESM projections, we have adopted the multi-model ensemble approach, which averages the results of all the models within each of the RCPs, and has been shown to generally give more reliable results (based on comparison of the modelled historical reconstruction versus observed data) than any particular model chosen randomly for any particular area (Mora et al, 2013). The results presented in this paper represent the general consensus among the various CIMP5 ESM projections.

Other sources of uncertainty also include the downscaling of the original model results to $1 \mathrm{~km}^{2}$, and the density of weather station networks from which the downscaled data has been spatially interpolated. This is particularly of issue within mountainous and very remote regions where reliable weather station data may be both spatially and temporally sparse. 


\section{Methods overview}

This report provides an overview of a geospatial analysis of projected climate change across the seven countries of central and south-central Asia. Results have been articulated for the whole of this region, and for each of seven countries. Although all four of the IPCC AR5 RCP have been modelled and analysed, for clarity of presentation, maps sometimes only show results for RCP 4.5 and RCP 8.5 (i.e. not all four of the RCPs), in keeping with common practice in the literature. All statistics for all four of the RCPs are given in the summary tables. It is generally agreed that RCP 2.6 (the best case scenario) is unlikely, given current global trends (IPCC, 2013). In general, comparing RCP 4.5 and 8.5 should provide the full realistic range of future climate projections. The concentration trajectory for RCP 6.0 does not diverge above RCP 4.5 until after 2060, and before then (i.e. 2050) is relatively similar to RCP 4.5 (Figure 1).

Figure 1: Illustration of the analysis used in determining the year of climate departure

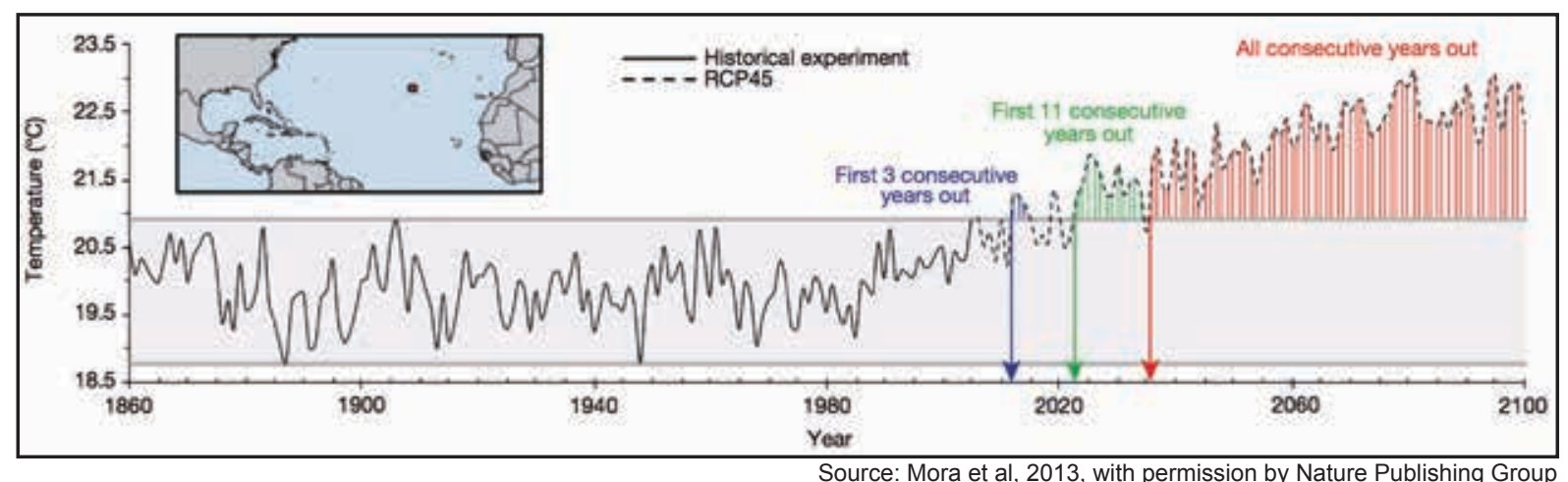

\section{Year of climate departure}

Most ecological and sociological systems can adapt to climate change over time, although this might not be the case for all species. However, the time frame in which climates will reach unprecedented states (i.e. climatic conditions not seen before in that location) may strongly determine the magnitude of disruption in ecosystems and the ability of species to adapt and avoid extinction. We use data provided by Mora et al (2013) to give an indication of the projected timing of climate departure. This index gives an estimate of the year when the climate (i.e. near-surface air temperature) exceeds the bounds of historical variability for a particular location, as determined by all consecutive years after that date being outside the bounds of variability over the past 140 years (Figure 1). Although this index gives a date in the future for unprecedented climatic conditions, this does not mean that change is not already occurring. Mora et al (2013) provide estimates for RCP 4.5 and RCP 8.5, based upon all 39 available CIMP5 models, at a resolution of $100 \mathrm{~km}^{2}$. When compared spatially, i.e. over the whole of central and south-central Asia, it can give an indication of the relative rate of warming by region and locale. The earlier the date of departure, the more rapid the rate of warming in that locale.

\section{Projected changes in temperature and precipitation}

An analysis, using a multi-model downscaled ensemble ( $\mathrm{n}=63)$ of CIMP5 Earth System Models (ESM) applied across four RCPs, has been used to assess climate change and its impact on temperature and growing conditions by the year 2050 within the 15 selected BSAP Priority Areas. We give the average results of all models within each RCP. A table of all CIMP 5 ESMs used in the analysis is given in Appendix 2. The RCPs represent the range of approved IPCC AR5 $\mathrm{CO}_{2}$ emission scenarios, with RCP 2.6 representing aggressive mitigation, and RCP 8.5 following a trajectory of 
"business as usual" (Figure 2). We have used the Worldclim meteorological dataset (Hijmans et al, 2005), which gives climate values based on data averaged from 1960 through 2000, as the current conditions baseline.

Figure 2: IPCC AR5 Representative Concentration Pathways (greenhouse gas concentration trajectories)

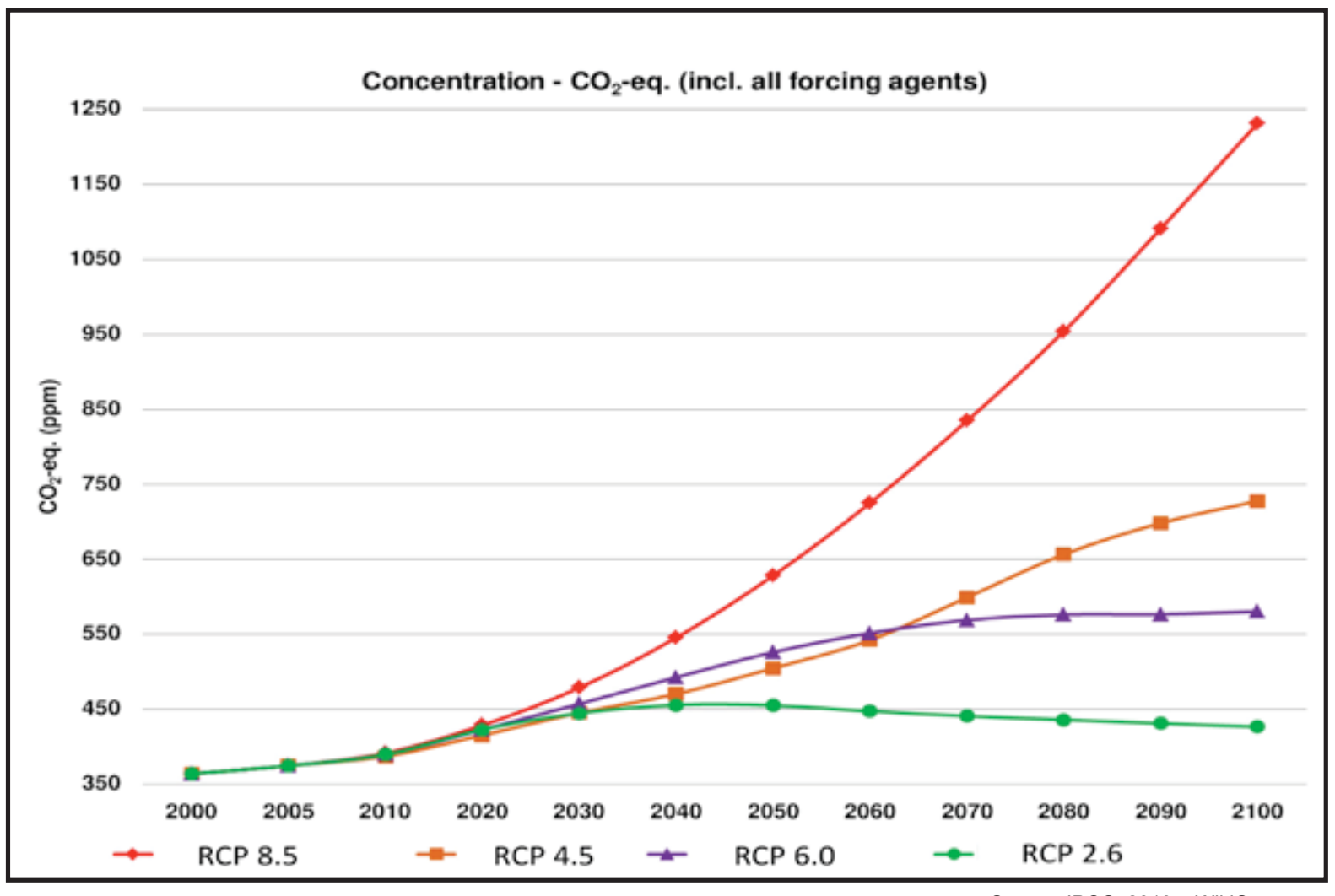

Source: IPCC, 2013 - WikiCommons

\section{Projected changes in potential evapotranspiration and aridity-wetness index}

For each priority area we provide an overview of the expected change in mean annual temperature, mean annual precipitation, mean annual potential evapotranspiration (PET), and the mean annual aridity-wetness index (AWI). The aridity-wetness index (AWI) is an integrative measure applicable to assess the moisture (precipitation) available for plant growth, i.e. after evapotranspiration. The higher the value of AWI, the more moisture is available. In general, 1.0 represents saturated conditions, i.e. more than enough water, and .65 is approximately a threshold for adequate moisture to support rain-fed agriculture under semi-arid conditions. It is based on a ratio of the amount of annual precipitation compared to the PET. The PET, which has been modelled individually based on each of the individual model projections for the entire region, is a measure of the total potential amount of transpiration (from plants) and evaporation (from soil) that can be expected under existing (or projected) temperature and relative humidity conditions. In short, PET is a measure of the ability of the atmosphere to remove water through ET processes, that is, transpiration by plants, and evaporation from soil and other water sources, such as interception of precipitation by the canopy. The AWI is calculated as the ratio of mean annual precipitation to the mean annual PET. A complete explanation of the methodology used to calculate PET is presented in Appendix 1, as per Zomer et al (2008). 


\section{In-situ soil-water balance model}

A simple water balance approach, using the ensemble of future climate projections, is used to estimate impacts on hydrological cycles at the regional scale, at a resolution of $1 \mathrm{~km}$. Hydrologic impacts of climate change are modelled and analysed in terms of in-situ soil-water balance and vapour flow response. The model is applied on a per-pixel basis to estimate spatially disaggregated biophysical conditions, and to predict hydrologic changes with change in future climate conditions. The spatially distributed water balance model is used to examine hydrological differences in actual evapotranspiration, soil water content and runoff. This model uses the average spatially distributed values of monthly precipitation and monthly potential evapotranspiration (PET), land use classes, soil depth and soil water holding capacity, and returns monthly spatially-distributed raster data representing actual evapotranspiration (AET), surface runoff (ROF) and soil water content (SWC). All the results are computed on a monthly basis throughout a year for current climate and future projected scenarios, and the results are aggregated into yearly figures. A complete explanation of the methodology used to calculate AET, ROF, and SWC is presented in Appendix 1, as per Zomer et al (2008).

\section{Environmental stratification and delineation of bioclimatic zones}

The Global Environmental Stratification (GEnS) classification and taxonomy (Metzger et al, 2013a), used as a contextual reference for our analysis, is a statistical stratification of the world's land surface into homogeneous bioclimatic strata facilitated by high-resolution global climate datasets, representing a considerable advance (Metzger et al, 2013a; 2013b; Sayre et al, 2014) over earlier global attempts at bioclimatic or ecosystems mapping (Holdridge, 1947; Thornthwaite, 1948; Peel et $\mathrm{al}, 2007)$. Based on a statistical clustering of significant climate variables, the GEnS provides a global stratification that can: a) quantitatively relate the spatial distribution of ecosystems to an identified set of bioclimatic parameters; b) provide a consistent methodology across landscapes and countries that have so far mostly been studied using different protocols, approaches and taxonomies; and c) allow for a statistical modelling of bioclimatic zonal shifts that can be used to estimate the direction and magnitude of impacts on ecosystems due to climatic changes.

The GEnS, based on high-resolution geospatial monthly climate datasets averaged from 1960 to 2000 (Hijmans et al, 2005), characterizes recent conditions to stratify the globe into 125 strata, aggregated into 18 zones. This quantitative approach allows for using an identified set of statistically significant parameters and the statistical profiles of the various strata to reconstruct the stratification based on projected future conditions (i.e. using the parameter values derived from modelled climate scenarios). The strata continue to represent bioclimatic conditions similar to the original strata (i.e. recent climatic conditions), but may shift in areal extent or location. The change in distribution of the bioclimatic strata is analysed and used as a surrogate measure to describe the potential projected macro-level impacts of climate change on bioclimatic conditions, and by extension, terrestrial ecosystems (Metzger et al, 2008; Zomer et al, 2013; 2014). When combined with other ecosystem, vegetation, or land use data, these shifts in spatial distribution can be interpreted in terms of projected impacts on ecosystems services, land use, wildlife habitats, risks to endemic or threatened species, or the risks and opportunities associated with future agricultural production.

The geospatial analysis and environmental stratification was performed in ArcGIS 10.2 (ESRI 2013) using the global datasets listed below, along with various national and local secondary datasets and information collected on land use and biodiversity, and a remote-sensing based land use change analysis described below, to corroborate and interpret results: 
- GEnS: Global Environmental Stratification v. 1

- WorldClim v. 1.4: Global high-resolution climate surfaces in 1950-2000

- CIMP-5: Ensemble of downscaled CIMP5 ESM models

- CGIAR-CSI Global Aridity and PET database

- SRTM: CGIAR-CSI SRTM Digital Elevation Model Database v. 4.1

\section{Modelling of projected future bioclimatic conditions}

Metzger et al (2013a) identified a set of significant bioclimatic parameters, based on a statistical screening of the various global climate datasets. Principal Component Analysis (PCA) of the global dataset revealed that $99.2 \%$ of the total variation was determined by four variables:

- $\mathrm{T}_{\text {mean } \mathrm{DD}>0}$ is defined as the annual sum of daily mean temperature degrees of days with a mean temperature above $0^{\circ} \mathrm{C}$, reflecting latitudinal and altitudinal temperature gradients, and plant growth periods (Hijmans et al, 2005);

- Aridity-Wetness Index (AWI) is defined as the ratio of annual precipitation over annual potential evapotranspiration (PET) and forms an expression of plant available moisture (Zomer et al 2008);

- Monthly Mean Temperature Seasonality is defined as the standard deviation of the monthly temperature means, and is a measure of temperature seasonality (Hijmans et al 2005);

- PET Seasonality is defined as the standard deviation of the monthly PET means, and is a measure of seasonality of plant available moisture (Zomer et al 2008).

These four bioclimatic variables were used as the input to the ISODATA clustering routine in ArcGIS to classify the GEnS environmental strata (Metzger et al, 2013a). Projected impacts have been modelled by reconstructing the stratification based upon current and future climate conditions, as modelled by an ensemble of 19 Earth System Models (ESM) provided by the Coupled Model Intercomparison Project - Phase 5 (CIMP5) (Meehl and Bony, 2011), using the same set of significant bioclimatic variables. The statistical signature profiles of the strata have been reconstructed for central and south-central Asia, based upon a multivariate analysis (maximum likelihood classification) of these four bioclimatic variables (using the original GEnS). These signature profiles were then used to reconstruct the current conditions (referred to as the CA_EnS) and to project the future spatial distribution of the CA-EnS strata based upon the CIMP5-modelled future climate conditions in 2050.

Four atmospheric greenhouse gas concentration trajectories, or representative concentration pathways (RCP) (Vuuren et al, 2011) were analysed using the CIMP5 model predictions for the year 2050 (average of 2040-2060), ranging from RCP 2.6 (aggressive mitigation/lowest emissions) to RCP 8.5 ("business as usual" scenario). CIMP5 model results were downscaled using the Delta method (Ramirez-Villegas and Jarvis, 2010) to 30 arc sec-resolution (equivalent to $\sim 1 \mathrm{~km}^{2}$ at the equator). The Maximum Likelihood Classification algorithm in ArcGIS 10.2 was used to construct the projected future spatial distribution of strata and zones, using the modelled future climate conditions as predicted by each of the emission scenario combinations $(n=63)$ as input parameters. All models within each RCP were combined into a majority ensemble result, using the class with the majority of occurrence within any particular grid cell as the class for that location. The rate of occurrence of other classes is used as a measure of the uncertainty among models. Mora et al (2013) tested the robustness of the CIMP5 model ensemble based on historical observation data (1985-2005) and found a high correlation when using multi-model averages. Other sources of uncertainty in our analysis include the difficulties associated with model predictions in highly heterogeneous terrain and landscape, such as the mountainous areas of central Asia. 


\section{Projected climate change}

\section{Year of climate departure}

The two countries of south-central Asia and south-eastern portions of central Asia (namely Tajikistan) appear to be approaching novel sets of bioclimatic conditions more rapidly than the northern portions of the region (Figure 3). The estimated year of climate departure for the various countries of the greater central and south-central Asia region ranges from the 2061 to 2086 under the more moderate RCP 4.5 emissions scenarios, and ranges from 2040 to 2054 under the "business as usual" RCP 8.5 scenario. This is slightly earlier than for the global average of 2069 for RCP 4.5 and 2047 for RCP 8.5 (Mora et al, 2013).

Figure 3: Year of climate departure showing central and south-central Asia. Darker colours are approaching the onset of novel climatic conditions relatively more rapidly than areas with lighter colours

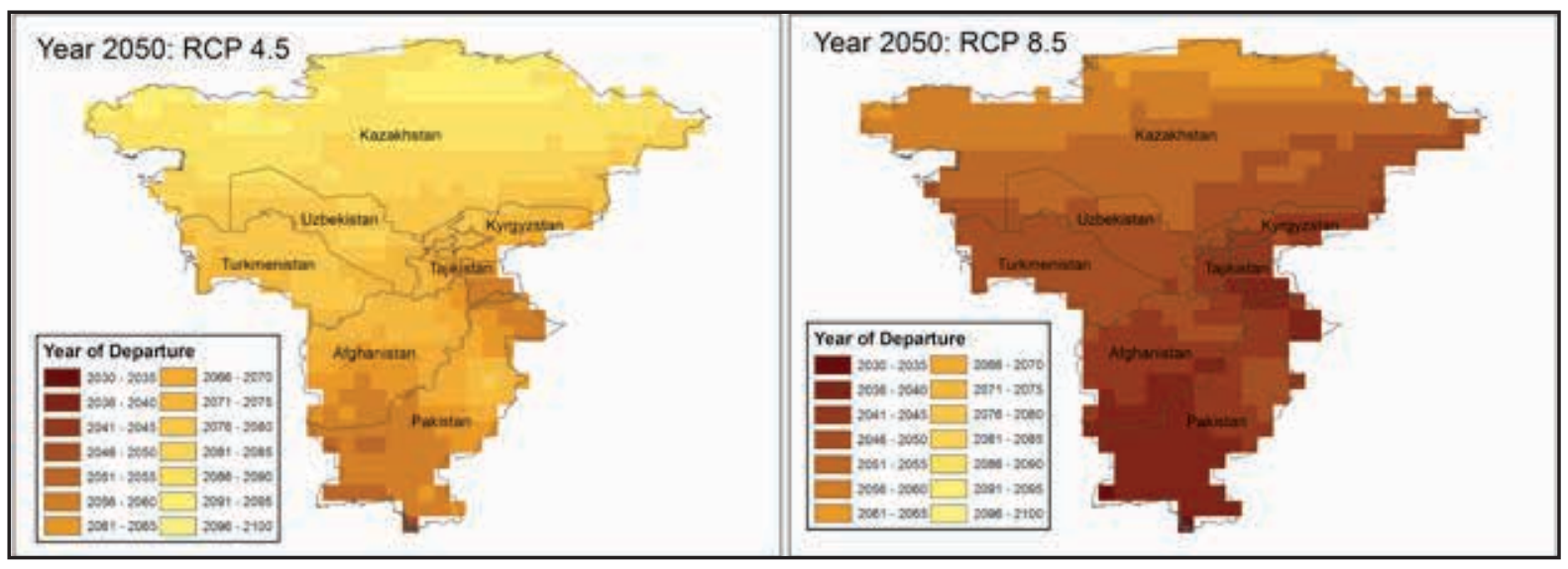

Data source: Mora et al, 2013

\section{Mean annual temperature}

The spatial distribution of mean annual temperatures for the region highlights the latitudinal temperature gradient, clearly discernible across the region from south to north, showing that the southern portions of these regions are substantially warmer. The higher elevations of the mountainous countries of Kyrgyzstan and Tajikistan, and the central regions of Afghanistan are reflected in their respective low mean annual temperatures. The farther north location of Kazakhstan is likewise reflected in colder temperatures. Projected temperature changes are evident across the region, with colder areas noticeably retreating, mountain tops warming, and a general warming trend seen moving north across the steppes of central Asia, with a marked expansion of warmer areas. 
Figure 4: Mean annual temperature across central and south-central Asia, showing current conditions (2000), based on spatially interpolated weather station data, averaged from 1960-2000, and as projected for the year 2050 under RCP 4.5 and RCP 8.5.
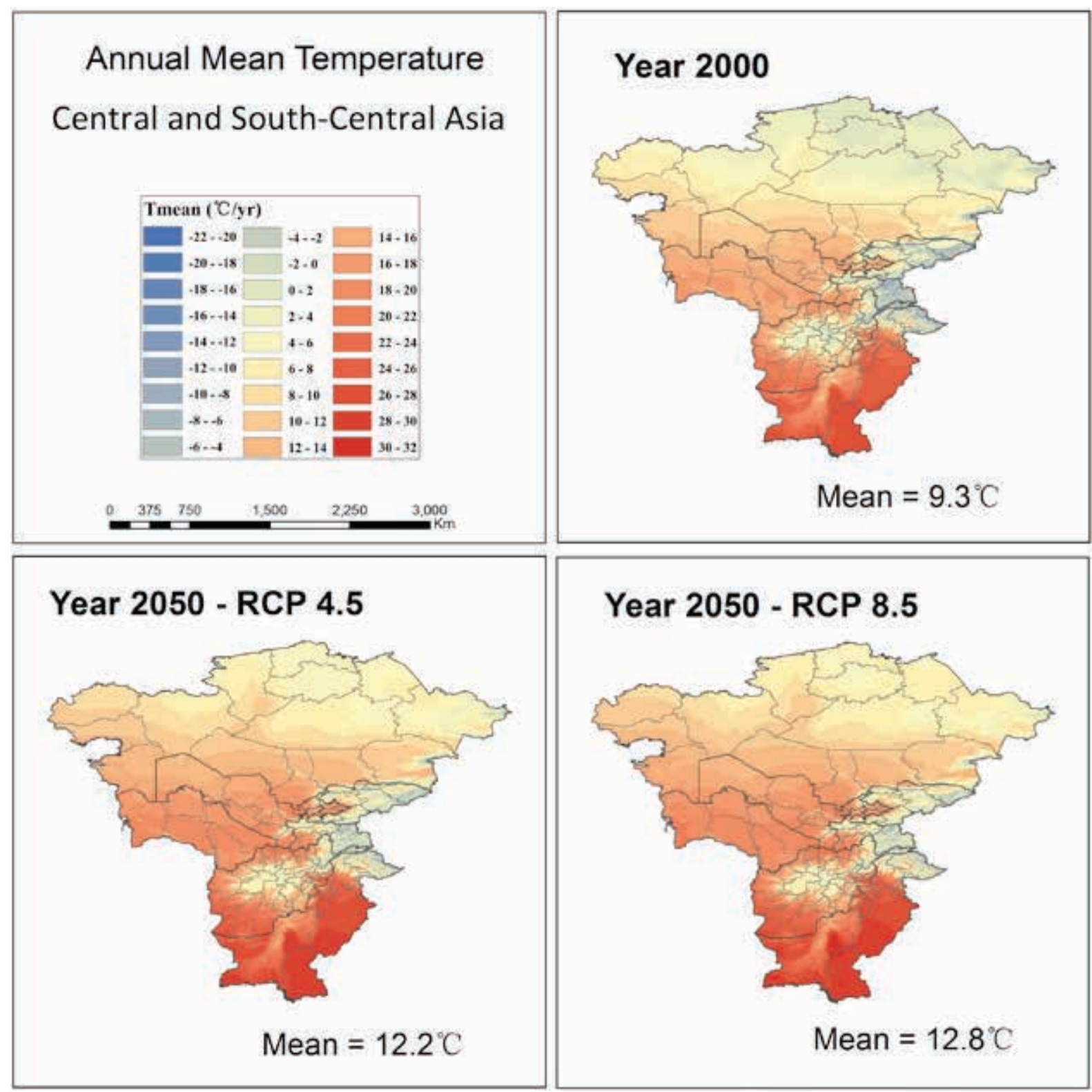

Averaged mean annual temperatures for the "current" period of 1960-2000 (referred to in the tables and maps simply as "2000") for the seven countries in the region ranged from a low of $1^{\circ} \mathrm{C}$ in Kyrgyzstan to $15.2^{\circ} \mathrm{C}$ in Turkmenistan, and over $20^{\circ} \mathrm{C}$ for Pakistan (Figure 4). By the year 2050, mean annual temperatures for these seven countries are projected to increase by, on average across the four emission scenarios (Figure 5), from $2.4^{\circ} \mathrm{C}$ to $3.2^{\circ} \mathrm{C}$. Kazakhstan shows the largest increase in temperature in the region, with Pakistan having the lowest (possibly due to the moderating influence of its proximity to the ocean). For the region overall, the average mean annual temperature of $9.3^{\circ} \mathrm{C}$ is projected to rise on average $2.9^{\circ} \mathrm{C}$, with the range of projections across the emission scenarios ranging from $2.4^{\circ} \mathrm{C}$ to $3.5^{\circ} \mathrm{C}$, with the "business as usual" RCP 8.5 scenario having the highest increases in temperature. 
Figure 5: Mean annual temperature for each of the countries in central and south-central Asia, and the region as a whole, showing current conditions, based on spatially interpolated weather station data, averaged for the period 1960-2000 (2000), and as projected for the year 2050, shown as an average of the four RCPs. Error bars indicate the range of projections across the four RCPs.

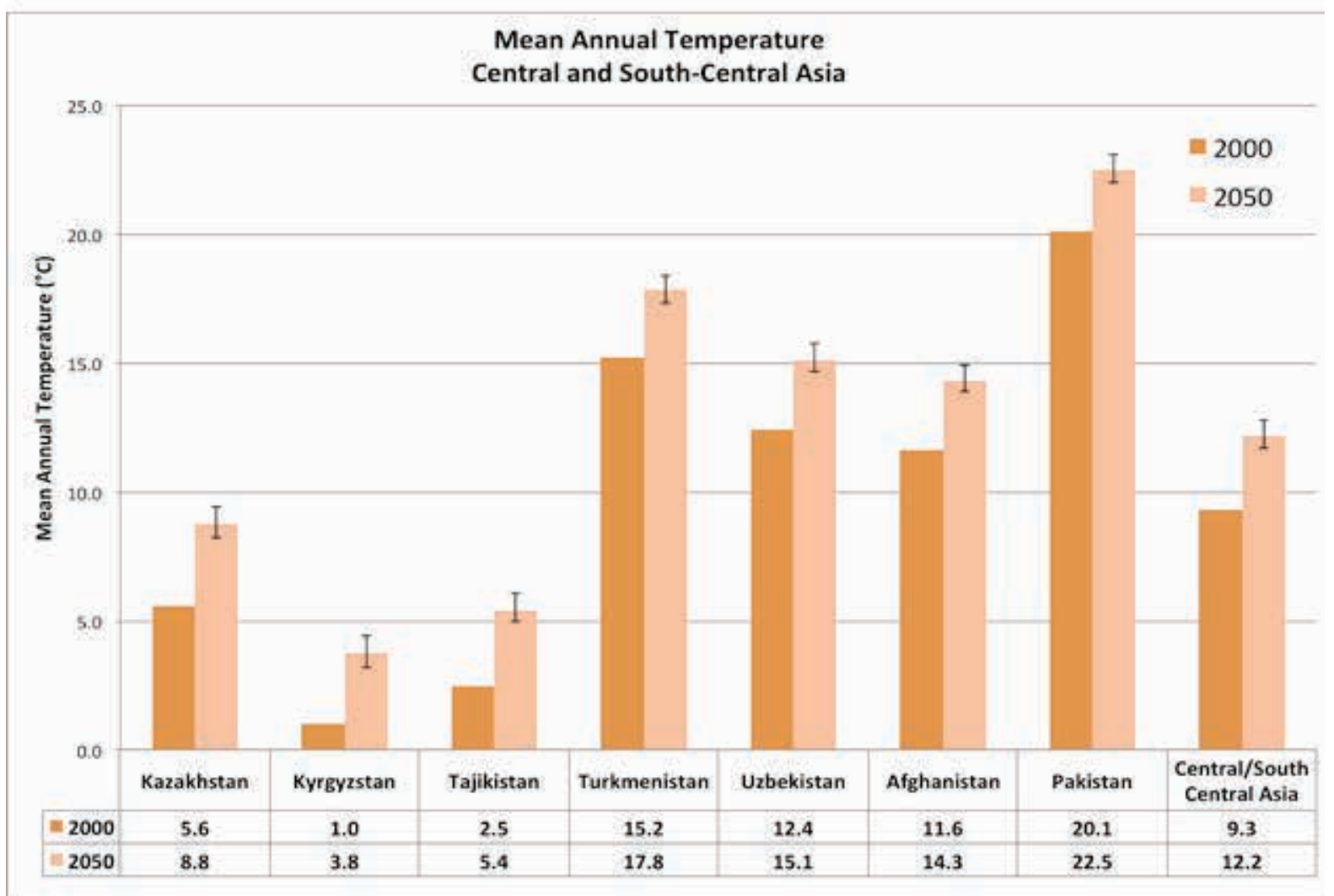

\section{Mean annual precipitation}

An overview of the spatial distribution of annual precipitation (Figure 6) reveals the important role of the relatively wet mountainous areas as water towers for the entire region. High levels of precipitation (e.g. more than $1000 \mathrm{~mm}$ annually) are found concentrated in these higher elevation areas, including northern Pakistan, eastern Afghanistan, Tajikistan, and Kyrgyzstan, while most of the rest of the region receives considerably less rainfall or snow. Along the latitudinal gradient, there appears to be an increase in precipitation while moving north or northeast. However, the overwhelming majority of higher rainfall areas are found in the mountainous east central part of the region. 
Figure 6: Mean annual precipitation across central and south-central Asia, showing current conditions (2000), based on spatially interpolated weather station data, averaged from 1960-2000, and as projected for the year 2050 under the RCP 4.5 and RCP 8.5.
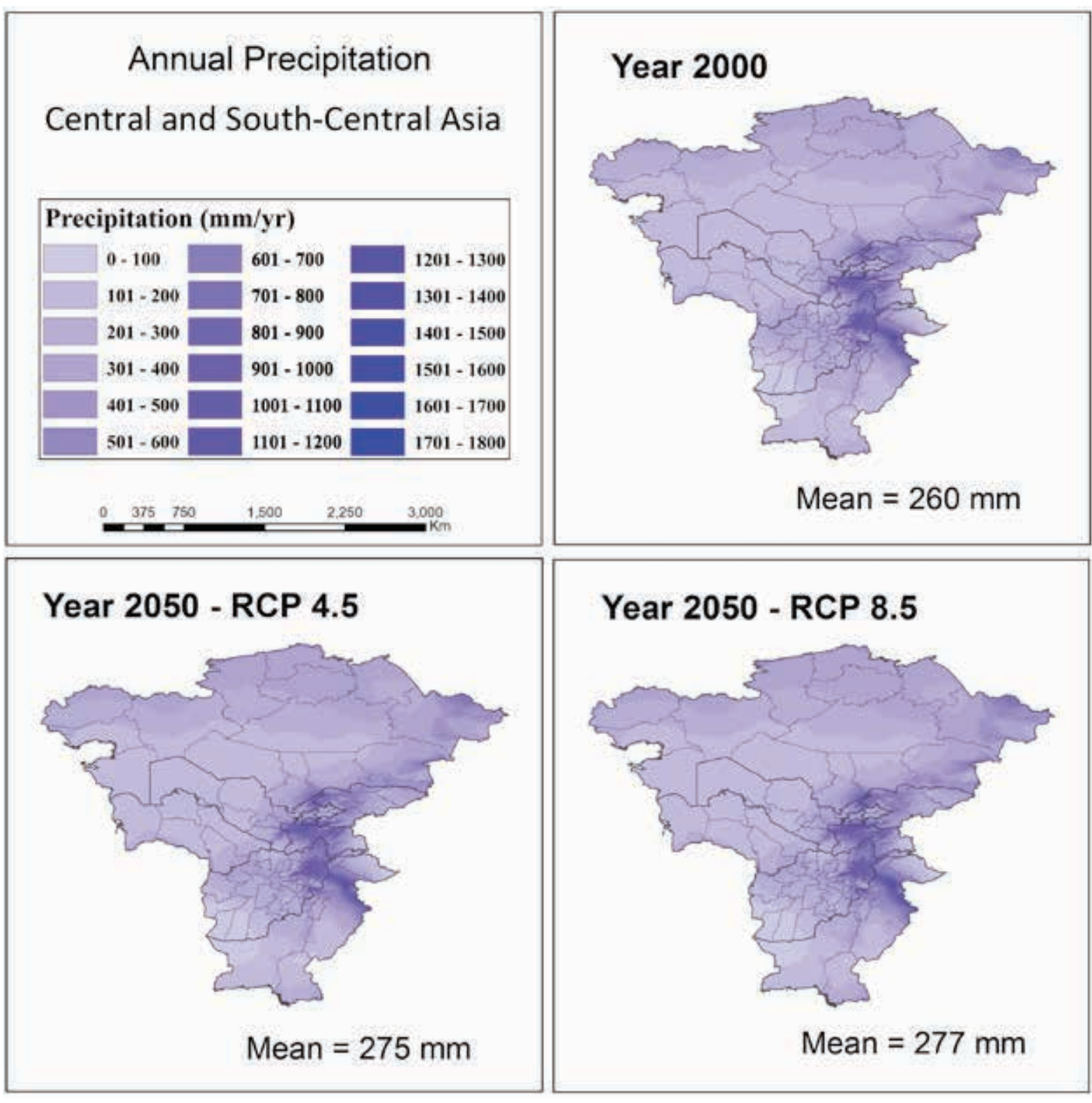

In general, the central and south-central Asia region is quite arid, with a mere $261 \mathrm{~mm}$ of annual precipitation for the region as a whole (Figure 7). Tajikistan receives the most precipitation in the region $(560 \mathrm{~mm})$ with Turkmenistan receiving the least $(163 \mathrm{~mm})$. Almost all countries of the region are projected to experience slight increases in precipitation, on average $26 \mathrm{~mm}$ by 2050, except for Afghanistan which is projected to experience a $10 \mathrm{~mm}$ decrease. Kyrgyzstan will see the largest increase $(30 \mathrm{~mm})$, with Turkmenistan remaining nearly the same with only a very slight increase $(3 \mathrm{~mm})$.

Overall, confidence levels in the precipitation projections of the CIMP5 Earth System Models are still quite low, with the variability among models generally higher than for the temperature projections. In our case, we have used the multi-model ensemble to aggregate, average, and to generally present a consensus view of the model results $(n=63)$. Although variability within the various results of any one RCP may be higher, there does, however, seem to be a strong convergence amongst the RCPs, as evidenced by the relatively narrow range across the four RCPs. 
Figure 7: Mean annual precipitation for each of the countries in central and south-central Asia, and the region as a whole, showing current conditions, based on spatially interpolated weather station data, averaged from 1960-2000 (2000), and as projected for the year 2050, shown as an average of the four RCPs. Error bars indicate the range of projections across the four RCPs.

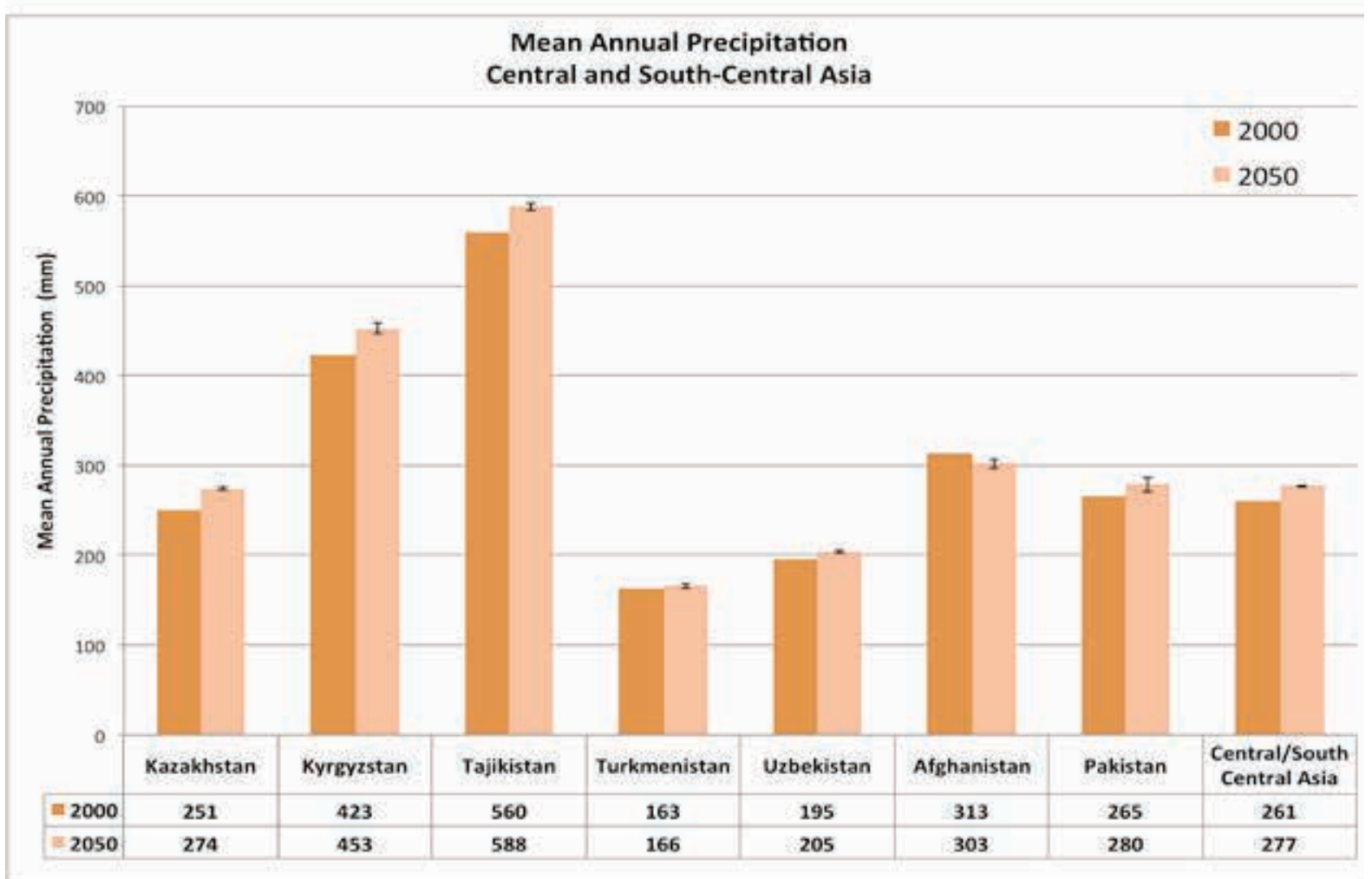

\section{Mean annual potential evapotranspiration (PET)}

High levels of potential evapotranspiration (PET) are evident across the region, with the highest PET found in the southern portions of Pakistan and Afghanistan, and markedly decreasing along the latitudinal gradient while moving north. Lower values are found in the colder high altitude zones.

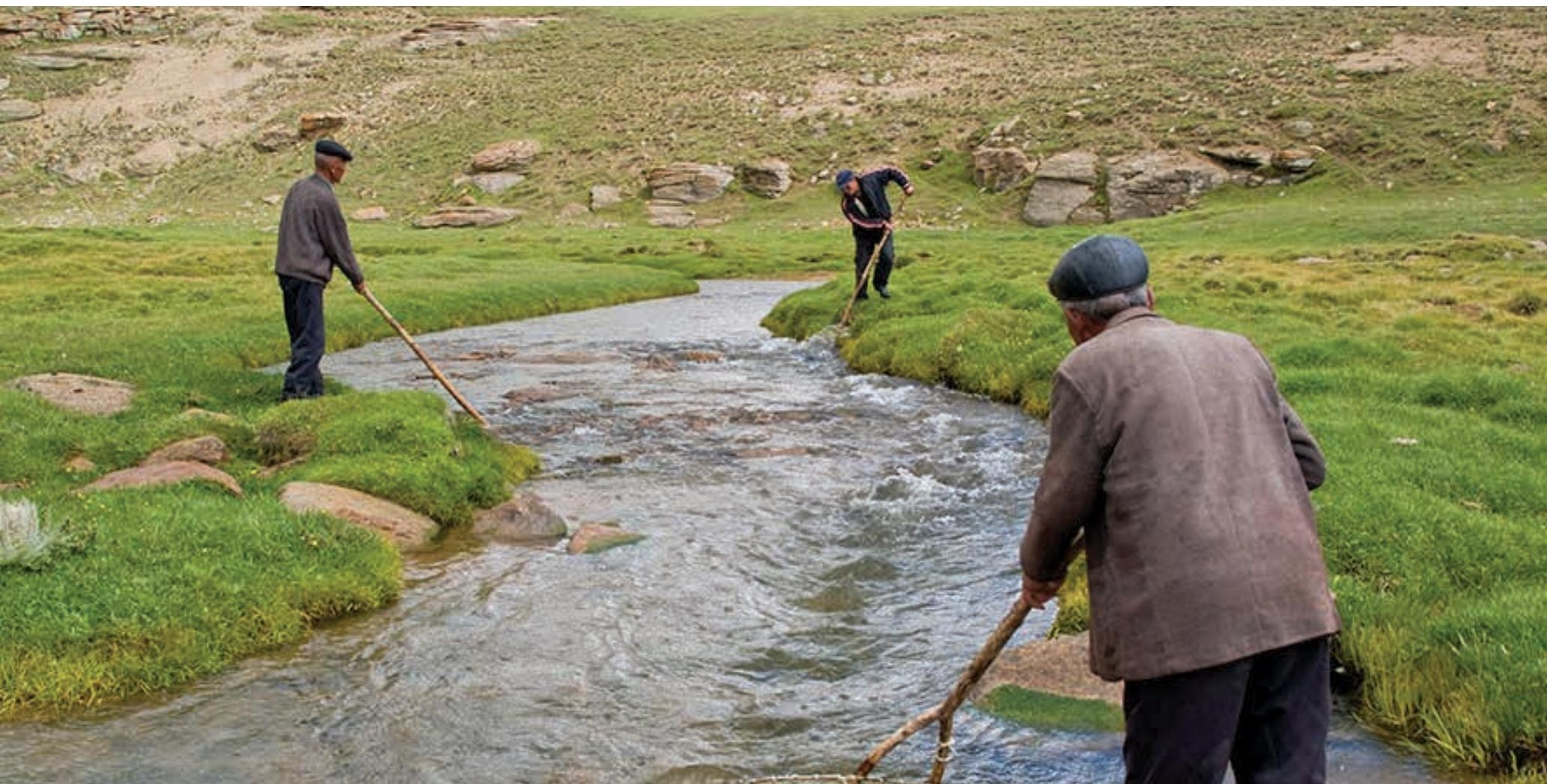


Figure 8: Mean annual potential evapotranspiration (PET) across central and south-central Asia, showing current conditions (2000), based on spatially interpolated weather station data, averaged from 1960-2000, and as projected for the year 2050 under the RCP 4.5 and RCP 8.5.
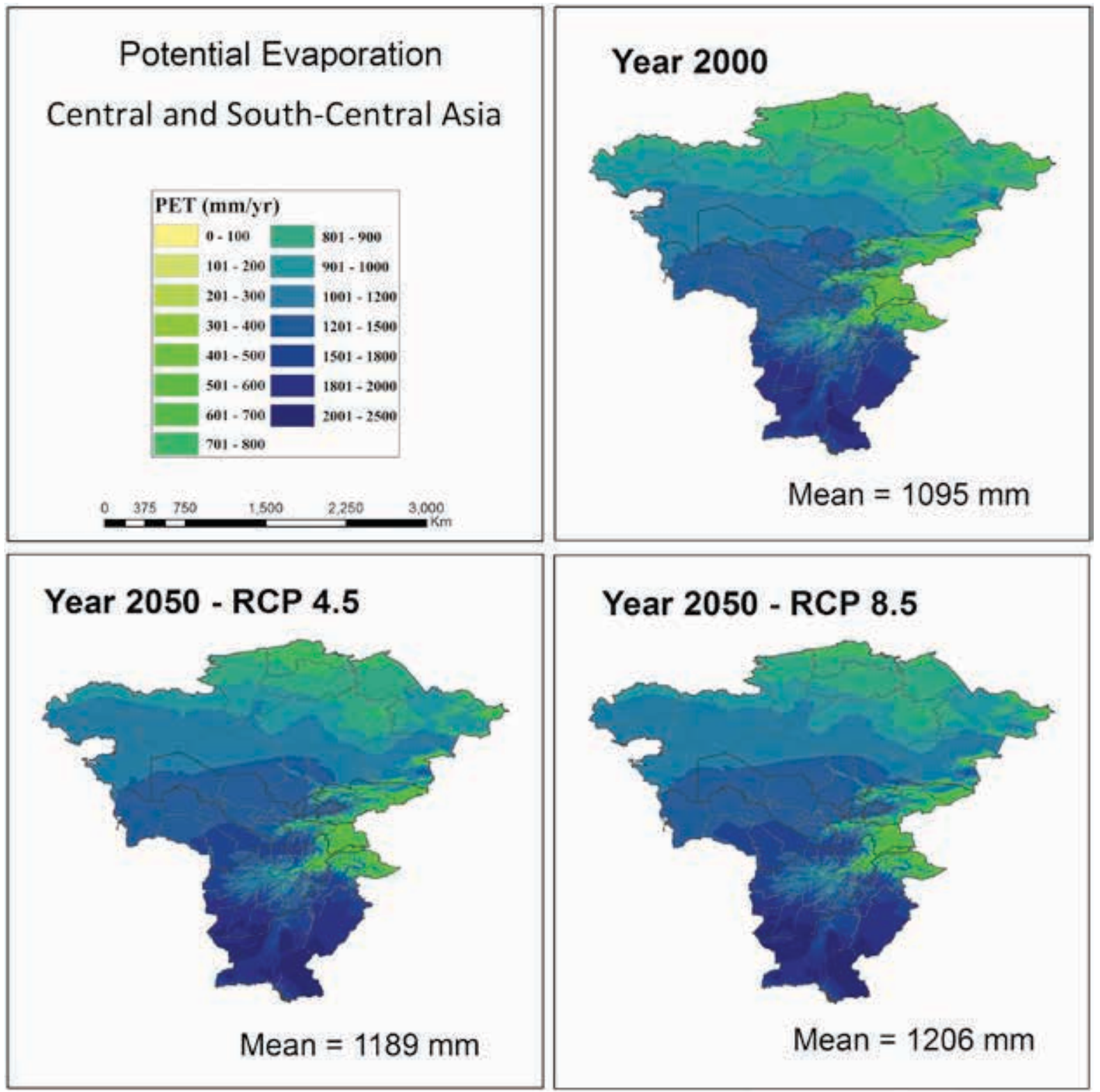

The averaged mean PET for the whole central and south-central Asia region of $1095 \mathrm{~mm}$ (1960-2000) increases by more than $8 \%$ to $1187 \mathrm{~mm}$ by 2050 , indicating potentially high water demand by both managed agricultural and pastoral systems, and natural (unmanaged or lesser managed) ecosystems. All seven countries within this region show a similar increase in PET, i.e. of approx. 8-9\% or just under $100 \mathrm{~mm}$ on average. Afghanistan shows the largest increase $(118 \mathrm{~mm})$, while Pakistan, with a high PET of $1629 \mathrm{~mm}$, increases by the least amongst the countries $(83 \mathrm{~mm})$ to the highest value of $1712 \mathrm{~mm}$, many times more than the $265 \mathrm{~mm}$ of precipitation it annually receives on average. These results seem to indicate that any benefit derived from increased precipitation will merely compensate for the increase in PET (driven by increasing temperatures). 
Figure 9: Mean annual potential evapotranspiration (PET) for each of the countries in central and south-central Asia, and the region as a whole, showing current conditions, based on spatially interpolated weather station data, averaged from 1960-2000 (2000), and as projected for the year 2050, shown as an average of the four RCP emission scenarios. Error bars indicate the range of projections across the four RCPs.

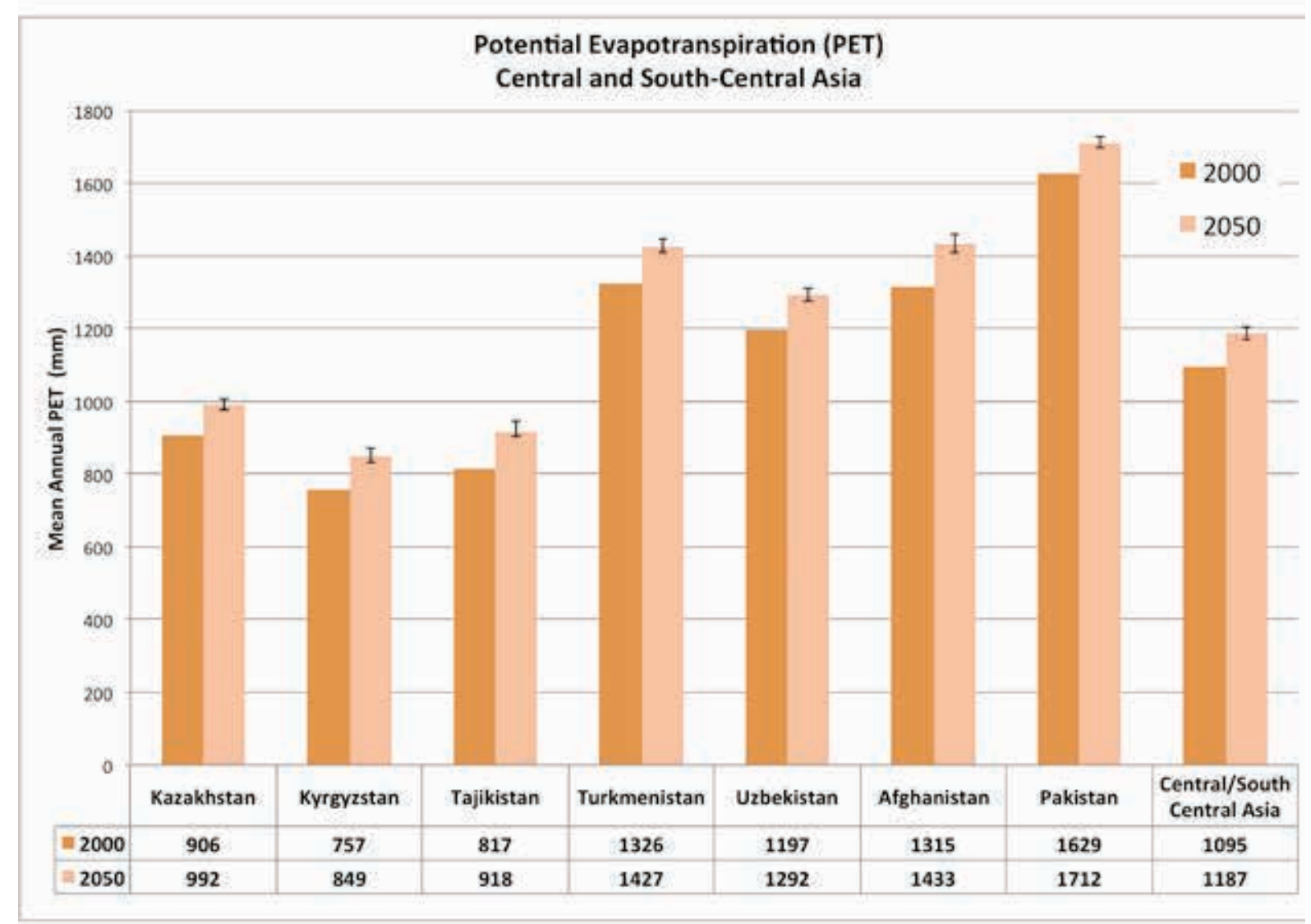

\section{Mean annual aridity-wetness index (AWI)}

The Aridity-Wetness Index (AWI; a unit-less measure) is a general indicator of bioclimatic and plant growth conditions, and is essentially a ratio of the amount of precipitation any one spot receives over the total PET, i.e. how much of the total PET requirement is satisfied by precipitation. Using this measure, 1.0 would indicate that the PET requirement was fully met, with 0.65 often used as a threshold for semi-arid conditions. Within this context, the mean AWI of 0.29 for the region indicates largely arid conditions. In the mountainous regions, however, there are spatially concentrated higher $(>1.0)$ AWI values, again underscoring the important role of these mountains as water towers for the region. AWI also increases along the latitudinal gradient towards the northern and north-eastern portions of the region.

Turkmenistan has the lowest AWI in the region (0.12), indicating a very severely arid climate, along with Uzbekistan (0.17), while Kyrgyzstan (0.60) and Tajikistan (0.84) have the more mesic climates in the region. All countries experience a decrease in AWI (indicating a more arid climate) by 2050. Turkmenistan and Uzbekistan only decrease very slightly, but Tajikistan decreases from 0.84 to 0.77 , indicating a significant trend towards increasing aridity for the region. It is assumed that any benefit of increased precipitation has been more than compensated for by an increased PET, leaving the more integrated measure of the AWI to decrease, both regionally, and for each of the individual countries. 
Figure 10: Mean annual Aridity-Wetness Index (AWI) across central and south-central Asia, showing current conditions (2000), based on spatially interpolated weather station data, averaged from 1960-2000, and as projected for the year 2050 under the RCP 4.5 and RCP 8.5 emission scenarios.
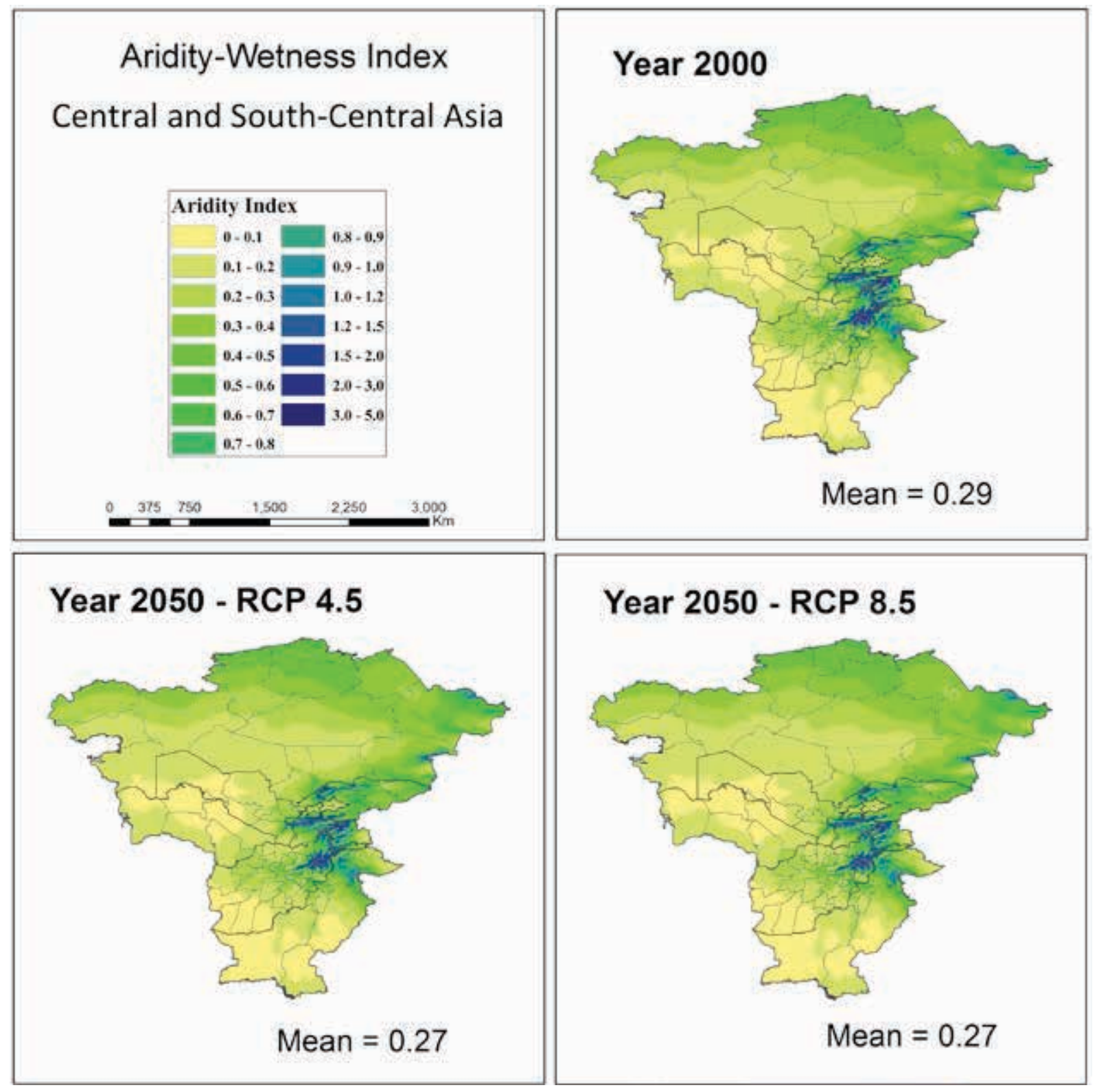

\section{In-situ hydrologic status: soil-water balance model}

A simple but spatially articulated soil-water balance approach has been used to model insitu hydrological status, divided into three basic components, namely vapour flow (actual evapotranspiration or AET), soil water content (SWC), and excess in-situ water, similar to "runoff" (ROF). Since the model only calculates in-situ (within the gird cell) processes and precipitation as the only input, without accounting for overland flow, we use "excess in-situ water" as the term for that portion of the input into the grid cell (i.e. precipitation), left over after actual evapotranspiration (AET) and accounting for water stored within the soil matrix (SWC) component. 
Figure 11: Mean annual Aridity-Wetness Index (AWI) for each of the countries in central and south-central Asia, and the region as a whole, showing current conditions, based on spatially interpolated weather station data, averaged from 1960-2000 (2000), and as projected for the year 2050, shown as an average of the four RCP emission scenarios. Error bars indicate the range of projections across the four RCPs.

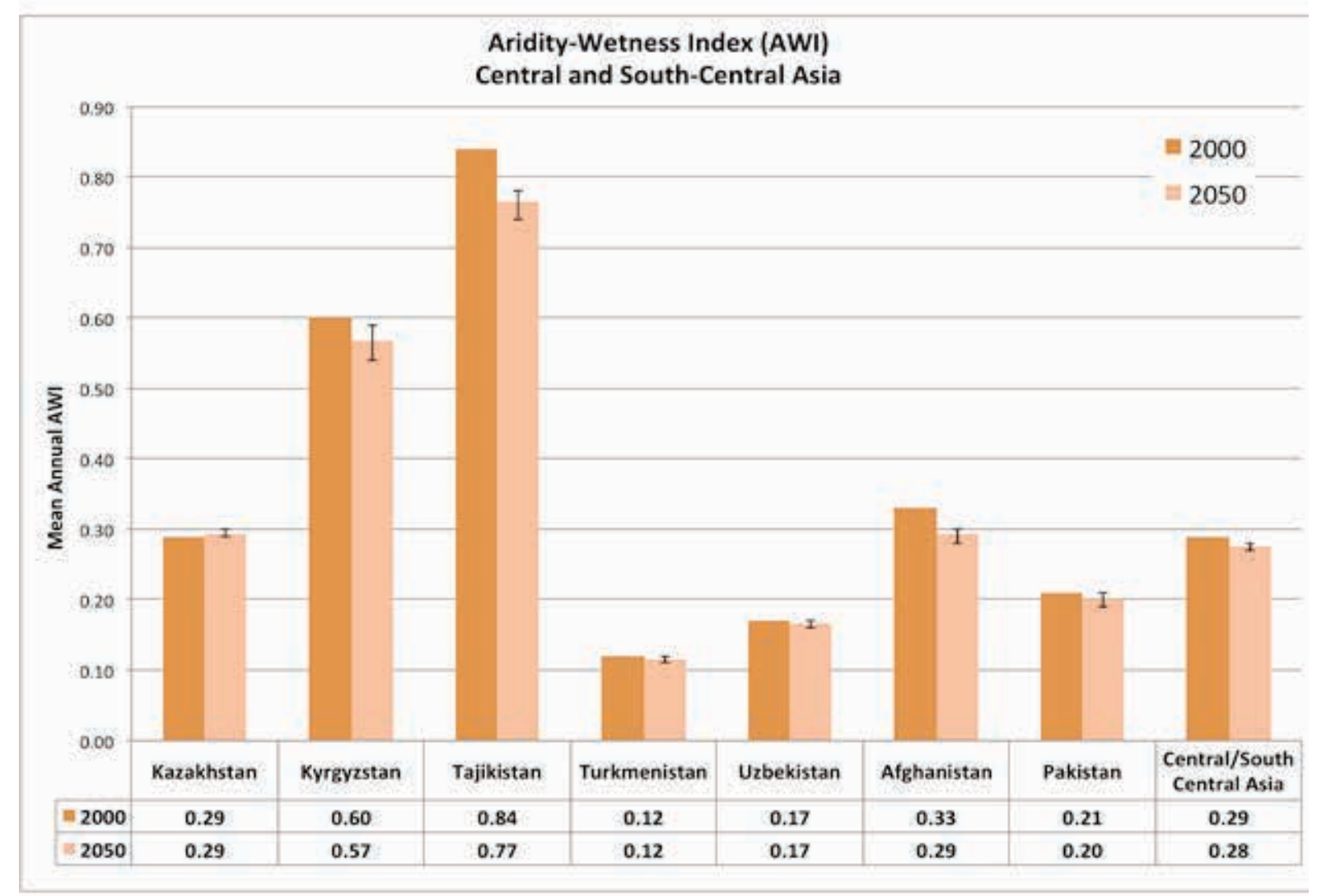

Annual vapour flow, or AET, differs from PET in that it takes land use and its specific evaporation and transpiration characteristics into account, providing an estimate of the actual amount of water evaporated and transpired, i.e. a value substantially lower than PET in water-limited environments, such as is evident throughout most of central and south-central Asia. An in-depth presentation of the hydrological modelling approach is described in Appendix 1.

As with PET, we see a slight increase in AET generally for all seven countries, averaging about 7\% for the region as a whole (Figure 12). Kyrgyzstan has the highest AET and Turkmenistan the lowest. However, values are similar across the region, that is, relatively low reflecting the arid and water limited environment.

The spatial modelling of the SWC component (Figure 13) revealed that northern portions of the region have generally wetter soil conditions, as do the higher elevations and more mountainous areas. In general, however, soil conditions are quite dry, with Kazakhstan $(40 \mathrm{~mm})$ and Kyrgyzstan $(31 \mathrm{~mm})$ having the moister soil conditions, although these levels are quite low. Particularly dry soil conditions, on average, are found in Turkmenistan $(12 \mathrm{~mm})$, and Pakistan $(13 \mathrm{~mm})$. SWC is not projected to 
Figure 12: Mean annual vapour flow (AET) across central and south-central Asia, showing current conditions (2000), based on spatially interpolated weather station data, averaged from 1960-2000, and as projected for the year 2050 under the RCP 4.5 and RCP 8.5.
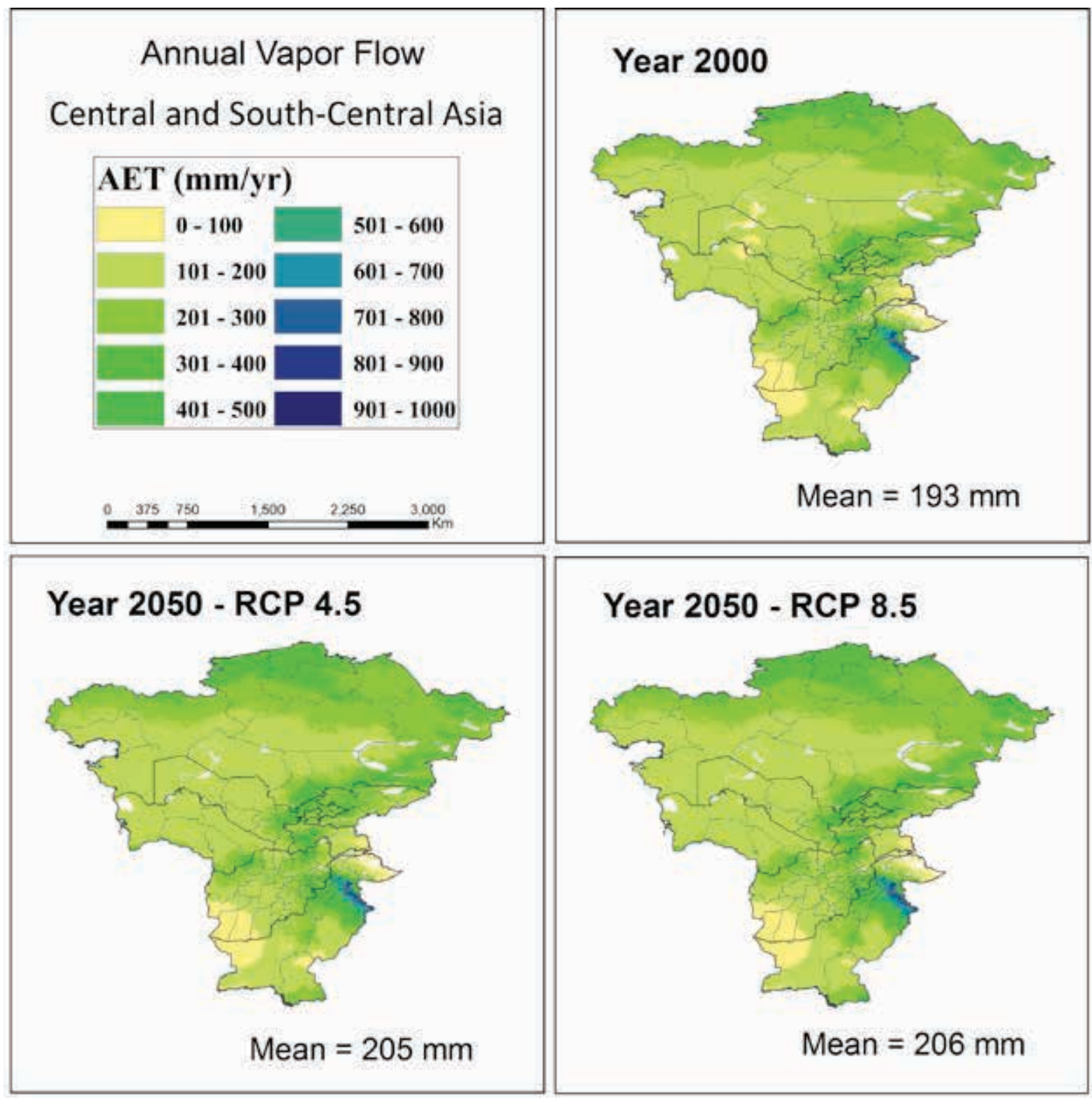

change much by 2050 , but this could be a bias of the model, as soil moisture conditions seem less sensitive to changes than other parameters.

Tajikistan $(359 \mathrm{~mm})$ has the highest excess in-situ water (ROF) in the region, followed by Kyrgyzstan $(189 \mathrm{~mm})$, with Turkmenistan $(15 \mathrm{~mm})$ having the lowest and least favourable moisture conditions. For the region as the whole (Figure 14), the average is a quite low $60 \mathrm{~mm}$, with concentrations of higher ROF values in the higher elevations. On a whole, there is very little change indicated in this water balance by 2050, primarily as high temperatures are increasing PET, and consequently AET, and slightly moister projected conditions are compensating for this increase in vapour flow. However, contrary to the AWI, the soil-water balance model projects a very slight (to non-existent) increase in in-situ excess water for all the regional countries, except Afghanistan, which experiences a slight decrease in ROF. However, the actual quantities (in mm) are minimal (Figure 15), but are amplified by the generally arid climatic conditions for the region. 
Figure 13: Mean annual soil water content (SWC) across central and south-central Asia, showing current conditions (2000), based on spatially interpolated weather station data, averaged from 1960-2000, and as projected for the year 2050 under the RCP 4.5 and RCP 8.5.
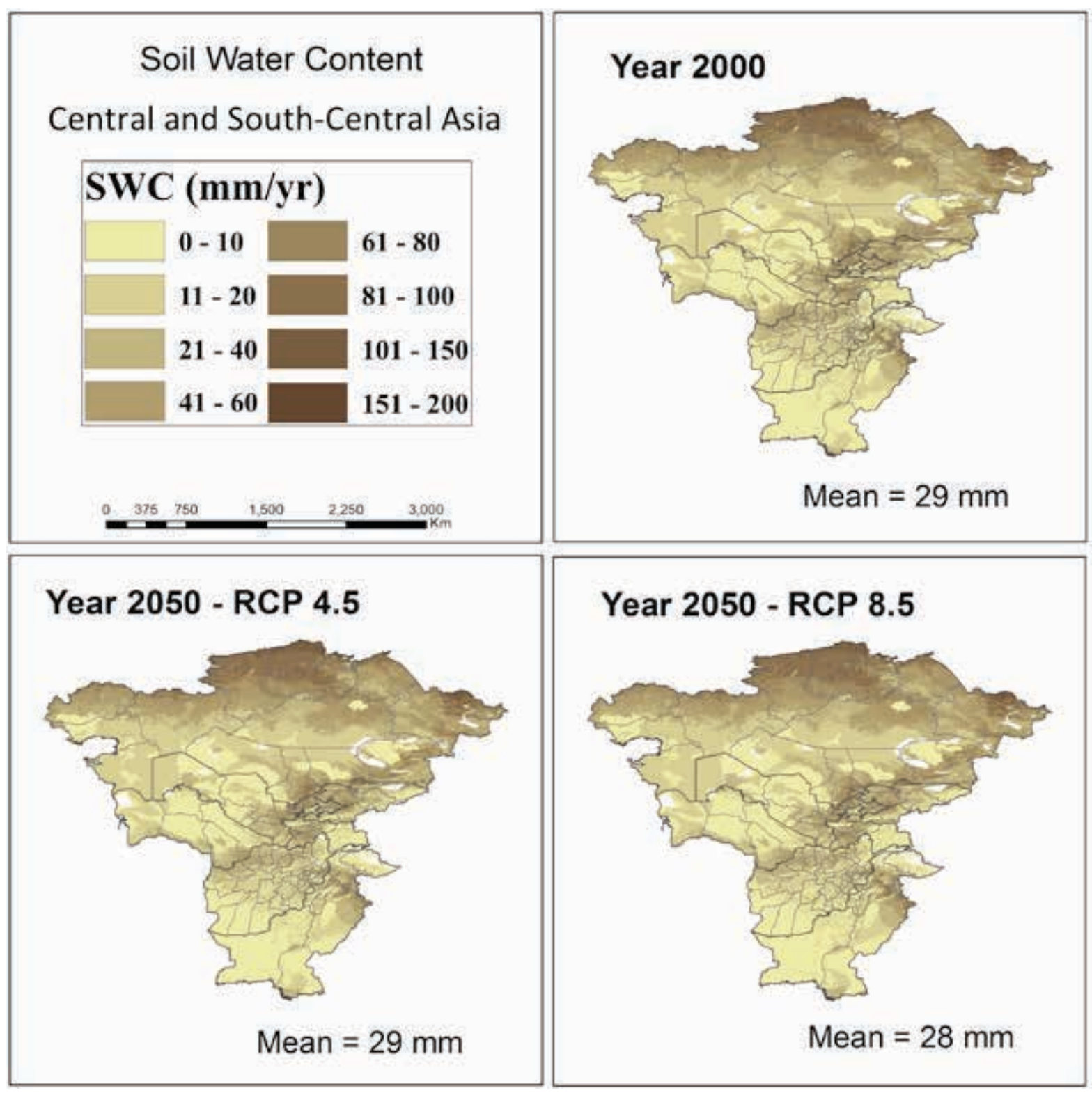


\section{Projected change in spatial distribution of bioclimatic conditions}

\section{Bioclimatic stratification}

Eighteen major bioclimatic zones were identified through this study as currently found within central and south-central Asia (Figure 16), ranging from Extremely Hot and Moist at low elevations in the south, to Extremely Cold and Wet zones at the higher elevations (Table 1). Mean annual temperatures for these zones are generally inversely correlated with their average elevation, however the zonal distribution of bioclimatic conditions also reflects a strong influence of latitudinal temperature and moisture gradients. Bioclimatic zones are generally dry to mesic (with the exception of the small area of Extremely Hot and Moist zone found primarily in Pakistan), reflecting the low average

Figure 14: Mean annual in-situ excess water (ROF) across central and south-central Asia, showing current conditions (2000), based on spatially interpolated weather station data, averaged from 1960-2000, and as projected for the year 2050 under the RCP 4.5 and RCP 8.5.
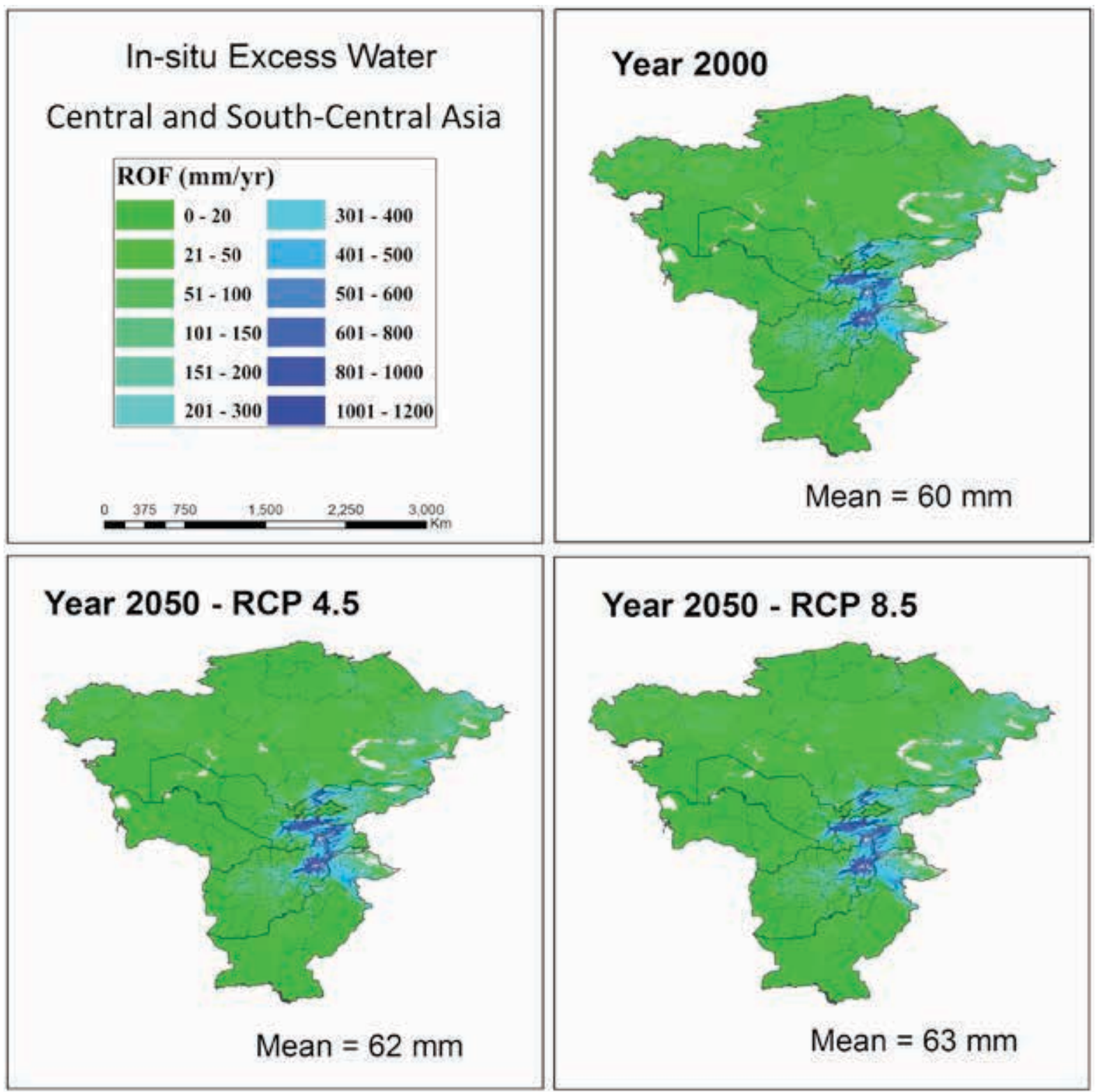
Figure 15: Mean annual vapour flow (AET), soil water content (SWC), and excess in-situ water (ROF) for each of the countries in central and south-central Asia, and the region as a whole, showing current conditions, based on spatially interpolated weather station data, averaged from 1960-2000 (2000), and as projected for the year 2050, shown as an average of the four RCPs. Error bars indicate the range of projections across the four RCPs.
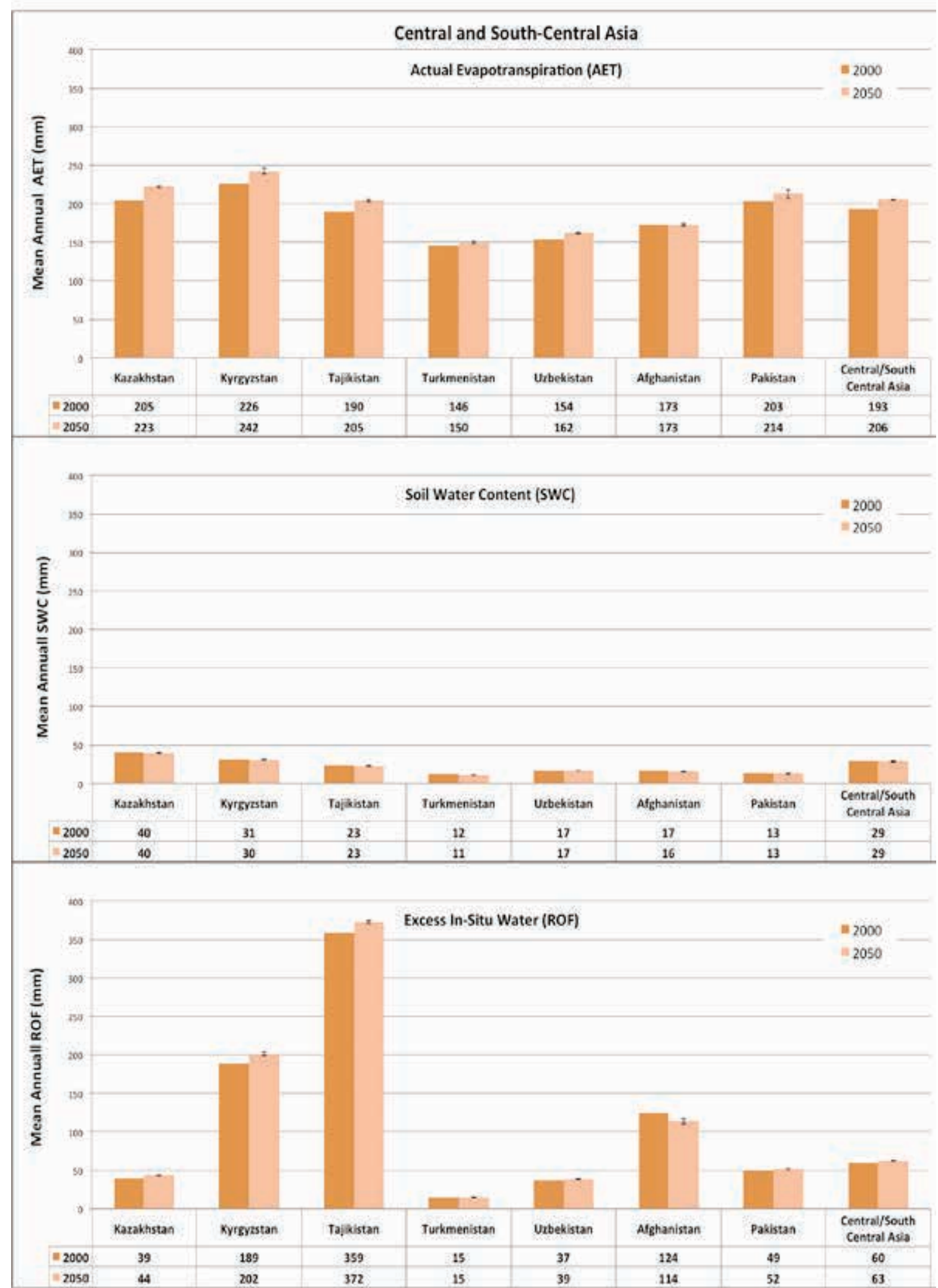
precipitation of the bioclimatic zones across the region. This is likewise evident in the AridityWetness Index, which indicates relatively dry to extremely dry conditions for all the zones except the highest elevation Cold and Wet to Extremely Cold and Wet zones.

The two Cool Temperate zones lying across the northern stretches of central Asia, with relatively low average elevation, comprise more than half of the combined central and south-central Asia region (58\%). Of the 18 zones, only 10 zones individually cover more than $1 \%$ of the total regional area, with the four most extensive zones (i.e. Cool Temperate and Warm Temperate) comprising more than $76 \%$ of the total area. Zones with smaller overall areal extent may nevertheless cover thousands of square kilometres and/or be important, for example as water source regions, or provide distinct bioclimatic conditions and niche habitat for biodiversity or specialized niche-specific agro-ecosystems.

\section{Projected change in spatial distribution of bioclimatic zones}

By the year 2050, substantial shifting and spatial displacement of the bioclimatic zones is seen across the region for all four RCPs (two of which, are shown in Figure 16; RCP 4.5 representing an "almost best case which can be hoped" for scenario, and RCP 8.5 being business as usual). Zones shift

Figure 16: Bioclimatic stratification of central and south-central Asia based on spatially interpolated weather station data averaged from 1960-2000, and two projected climate change scenarios (RCP 4.5 and RCP 8.5) for the year 2050 .

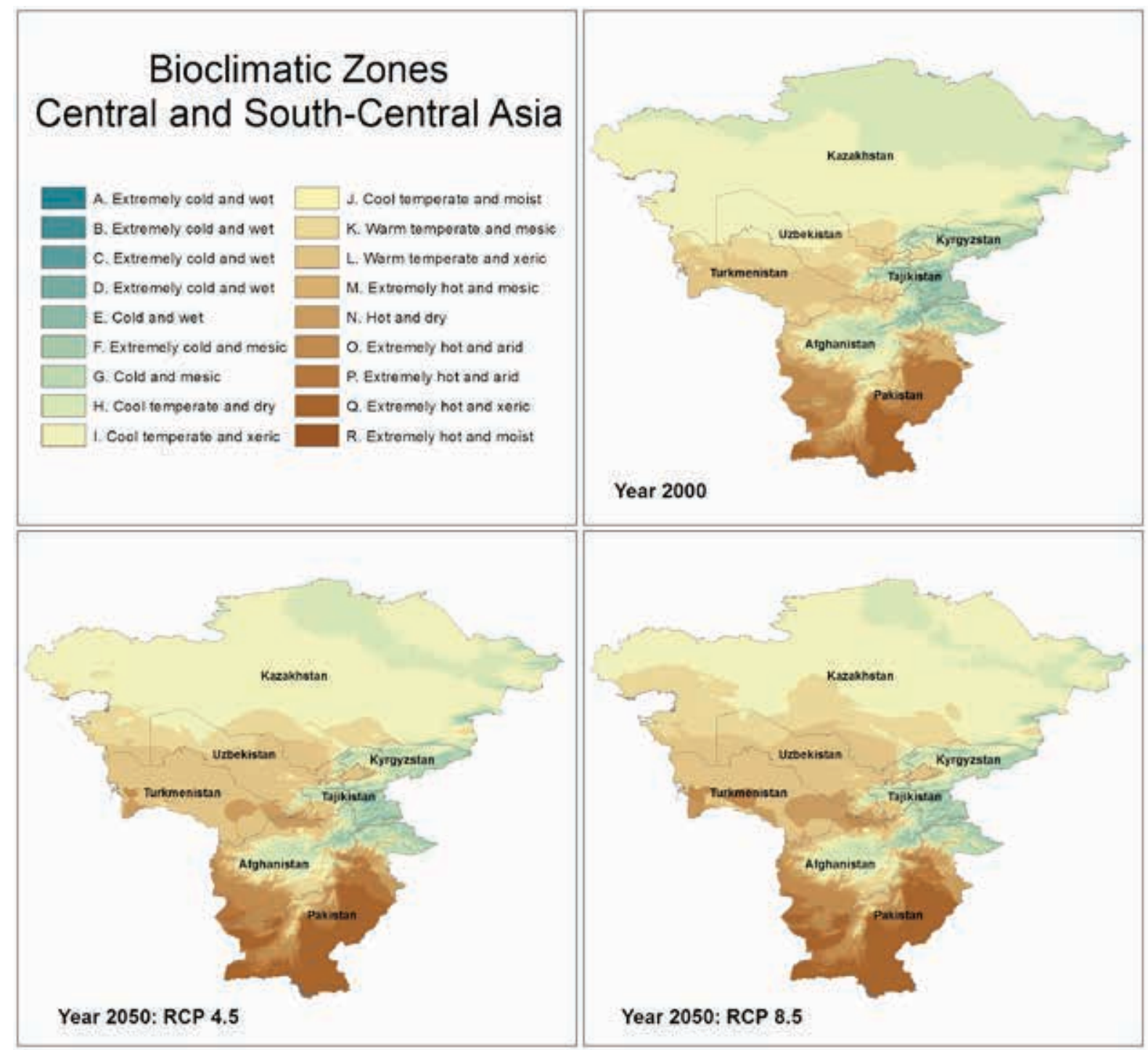


Table 1: Basic climatic characteristic of the CA_EnS bioclimatic zones, including the areal extent of the zone (Area), including as a percentage of the total area of the whole region, the mean elevation (Elevation), mean annual temperature (Temperature), mean annual potential evapotranspiration (PET), and the mean annual aridity-water index (AWI).

\begin{tabular}{|c|c|c|c|c|c|c|c|}
\hline \multirow[t]{2}{*}{ Bioclimatic Zone } & \multicolumn{2}{|c|}{ Area } & \multirow{2}{*}{$\begin{array}{c}\text { Elevation } \\
\text { (masl) }\end{array}$} & \multirow{2}{*}{$\begin{array}{c}\text { Temperature } \\
\left({ }^{\circ} \mathrm{C}\right)\end{array}$} & \multirow{2}{*}{\begin{tabular}{|c|} 
Precipitation \\
$(\mathrm{mm})$
\end{tabular}} & \multirow{2}{*}{$\begin{array}{l}\text { PET } \\
(\mathrm{mm})\end{array}$} & \multirow[t]{2}{*}{ AWI } \\
\hline & (sq.km.) & $\%$ & & & & & \\
\hline Extremely cold and wet & 6 & 0.00 & 6,537 & $(14.6)$ & 899 & 219 & 4.16 \\
\hline Extremely cold and wet & 962 & 0.02 & 5,905 & $(13.4)$ & 824 & 259 & 3.30 \\
\hline Extremely cold and wet & 1,427 & 0.03 & 5,969 & $(13.6)$ & 456 & 270 & 1.67 \\
\hline Extremely cold and wet & 24,354 & 0.44 & 4,794 & $(7.7)$ & 808 & 420 & 1.96 \\
\hline Cold and wet & 16,340 & 0.30 & 4,462 & $(4.9)$ & 907 & 471 & 1.95 \\
\hline Extremely cold and mesic & 237,334 & 4.30 & 3,948 & $(3.8)$ & 447 & 564 & 0.79 \\
\hline Cold and mesic & 210,363 & 3.81 & 2,603 & 0.9 & 500 & 754 & 0.67 \\
\hline Cool temperature and dry & $1,285,448$ & 23.30 & 722 & 3.2 & 314 & 826 & 0.38 \\
\hline Cool temperature and xeric & $1,894,055$ & 34.33 & 321 & 8.8 & 196 & 1,036 & 0.19 \\
\hline Cool temperature and moist & 11,579 & 0.21 & 2,358 & 9.9 & 823 & 1,001 & 0.83 \\
\hline Warm temperatate and mesic & 476,481 & 8.64 & 638 & 14.0 & 252 & 1,297 & 0.20 \\
\hline Warm temperatate and xeric & 542,022 & 9.82 & 485 & 16.2 & 209 & 1,413 & 0.15 \\
\hline Extremely hot and mesic & 38,394 & 0.70 & 425 & 22.5 & 682 & 1,616 & 0.42 \\
\hline Hot and dry & 136,737 & 2.48 & 1,046 & 19.6 & 240 & 1,698 & 0.15 \\
\hline Extremely hot and arid & 217,657 & 3.94 & 765 & 22.3 & 127 & 1,844 & 0.07 \\
\hline Extremely hot and arid & 247,806 & 4.49 & 227 & 25.0 & 213 & 1,826 & 0.12 \\
\hline Extremely hot and xeric & 174,825 & 3.17 & 59 & 26.8 & 163 & 1,938 & 0.08 \\
\hline Extremely hot and moist & 1,628 & 0.03 & 260 & 23.8 & 915 & 1,627 & 0.56 \\
\hline
\end{tabular}

both upslope and northward. The largest zone in areal extent (Cool Temperate and Xeric) increases substantially (Figure 17), by as much as $87,000 \mathrm{~km}^{2}$, as do both the Warm Temperate zones which together increase by over $400,000 \mathrm{~km}^{2}$. In contrast to this, the Cool Temperate and Dry zone decreases by almost half, or more than $640,000 \mathrm{~km}^{2}$. The very small area of Extremely Hot and Moist (just over $1500 \mathrm{~km}^{2}$ ) disappears completely by 2050 . The four Extremely Cold and Wet zones decrease by more $50 \%$ in areal extent, and viewed along the temperature gradient, all the zones cooler than the Cool Temperate, including all the Cold and the Extremely Cold zones decrease in size.

On average, the average mean elevation of all the bioclimatic zones shifts upward by $220 \mathrm{~m}$ (Table 2). However, not all zones shift upward. Three zones shift their mean elevation downward (in conjunction with significant spatial displacement). Upward shifting of both the mean elevation, and the minimum and maximum elevations are more evident in the cool to colder zones (Figure 18), which are also the higher elevation zones found primarily in the mountainous regions, several of which shift in excess of 500 metres upward in mean elevation. Almost all of the zones shift upward substantially in their maximum elevational extent, and most also shift upward in their minimum elevational extent (or at least stay approximately at the same minimum elevation). The warmer zones all increase the extent of their elevational range substantially.

A similar distribution is seen in the latitudinal range and mean latitude of the CA_EnS bioclimatic zones (Figure $19 \&$ Table 3 ). The coldest and higher elevation zones, restricted to the mountain do not show the latitudinal shift, however most of the warmer and lower elevation zones show a pronounced northward shift in their mean latitudinal range, average of $87 \mathrm{~km}$ northward (for all zones). Likewise, there is a large shift in maximum northward latitude of $102 \mathrm{~km}$ on average. A few zones also show a southerly expansion of their range as well, however, the average southern limit of bioclimatic zones moves northward by $62 \mathrm{~km}$. 
Figure 17: Areal extent of the CA_EnS bioclimatic zones under current (averaged 1960-2000) bioclimatic conditions, and by the year 2050, as averaged over all four RCP emission scenarios. Error bars indicate the range of projections across the four RCPs.
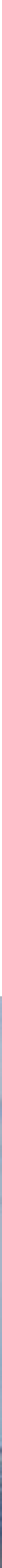
Figure 18: Maximum, mean, and minimum elevation of the CA_EnS bioclimatic zones under current (averaged 1960-2000) bioclimatic conditions, and by the year 2050, as averaged over all four RCP emission scenarios. Bar in the middle of the column indicates the mean elevation of that bioclimatic zone. Minimum elevation exceeded $-134 \mathrm{~m}$ (not indicated on this graph).

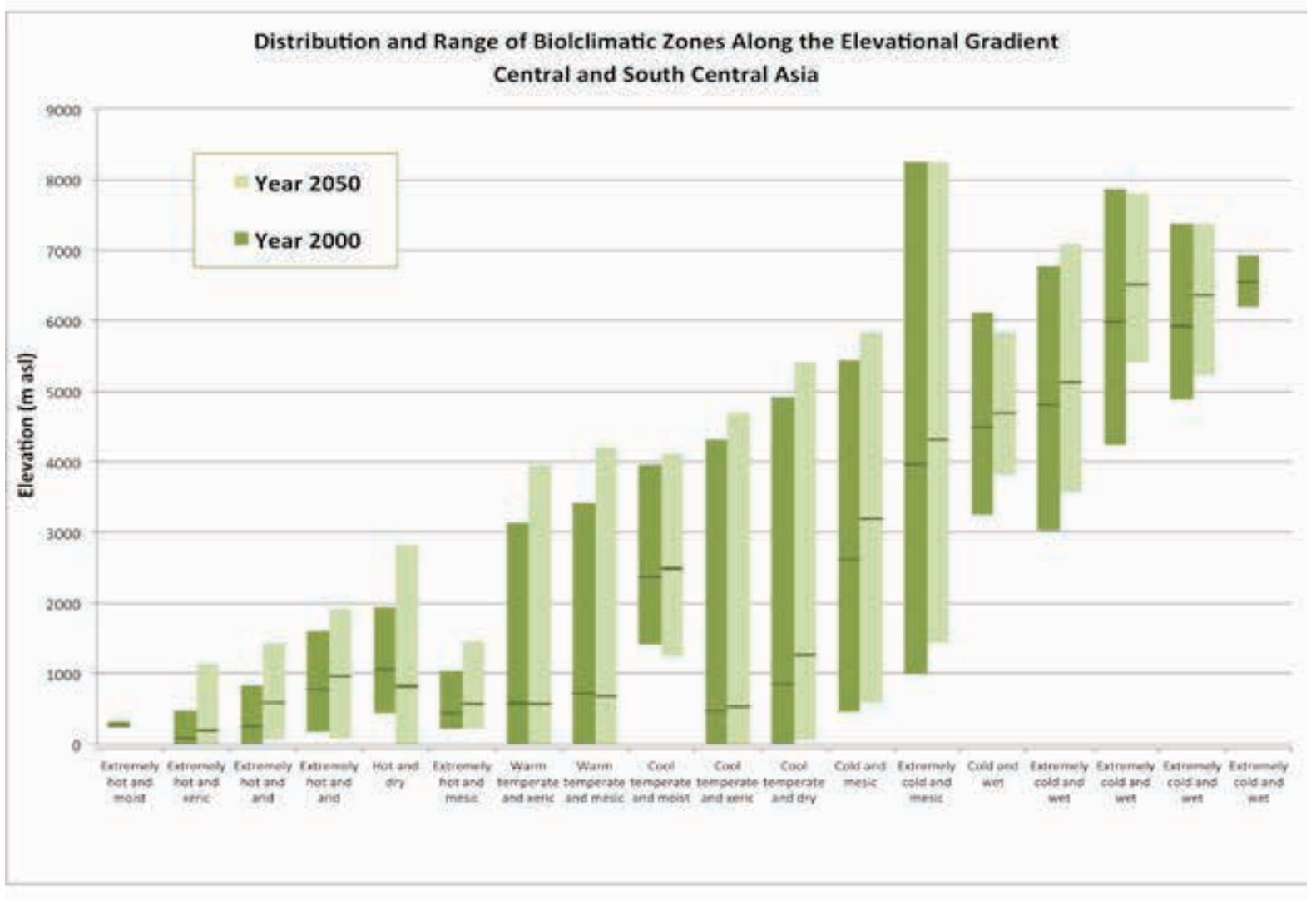

Table 2: Mean elevation of the CA_EnS bioclimatic zones under current (averaged 1960-2000) bioclimatic conditions, and mean upward shift under 4 emission scenarios, and as averaged across all 4 scenarios, by the year 2050 .

\begin{tabular}{|c|c|c|c|c|c|c|}
\hline \multirow[t]{2}{*}{ CA_EnS Zone } & \multirow{2}{*}{$\begin{array}{c}\begin{array}{c}\text { Mean } \\
\text { Elevation }\end{array} \\
\text { (masl) }\end{array}$} & \multicolumn{5}{|c|}{ Year 2050 - Upward Shift (m) } \\
\hline & & $\begin{array}{l}\text { RCP } 2.6 \\
\text { Elevation }\end{array}$ & $\begin{array}{c}\text { RCP } 4.5 \\
\text { Temperature }\end{array}$ & $\begin{array}{c}\text { RCP } 6.0 \\
\text { Precipitation }\end{array}$ & RCP 8.5 & RCP Avg \\
\hline Extremely cold and wet & 6,537 & - & - & - & - & - \\
\hline Extremely cold and wet & 5,905 & 360 & 462 & 388 & 545 & 439 \\
\hline Extremely cold and wet & 5,969 & 436 & 556 & 513 & 621 & 532 \\
\hline Extremely cold and wet & 4,794 & 252 & 323 & 312 & 381 & 317 \\
\hline Cold and wet & 4,462 & 130 & 193 & 185 & 362 & 218 \\
\hline Extremely cold and mesic & 3,948 & 306 & 363 & 333 & 442 & 361 \\
\hline Cold and mesic & 2,603 & 464 & 579 & 518 & 711 & 568 \\
\hline Cool temperature and dry & 722 & 307 & 569 & 371 & 867 & 529 \\
\hline Cool temperature and xeric & 321 & 46 & 60 & 46 & 126 & 70 \\
\hline Cool temperature and moist & 2,358 & 101 & 147 & 76 & 138 & 116 \\
\hline Warm temperatate and mesic & 638 & 11 & $(72)$ & 7 & $(230)$ & $(71)$ \\
\hline Warm temperatate and xeric & 485 & $(58)$ & $(54)$ & $(59)$ & $(54)$ & (56) \\
\hline Extremely hot and mesic & 425 & 23 & 202 & 88 & 224 & 134 \\
\hline Hot and dry & 1,046 & $(127)$ & $(297)$ & $(244)$ & $(410)$ & $(270)$ \\
\hline Extremely hot and arid & 765 & 189 & 222 & 200 & 98 & 177 \\
\hline Extremely hot and arid & 227 & 263 & 355 & 311 & 470 & 350 \\
\hline Extremely hot and xeric & 59 & 81 & 124 & 90 & 167 & 116 \\
\hline Extremely hot and moist & 260 & - & - & - & - & - \\
\hline Aver & pward Shift & 174 & 233 & 196 & 279 & 220 \\
\hline
\end{tabular}


Figure 19: Mean latitude of the CA_EnS bioclimatic zones under current (averaged 1960-2000) bioclimatic conditions, and by the year 2050, as averaged over all four RCP emission scenarios.

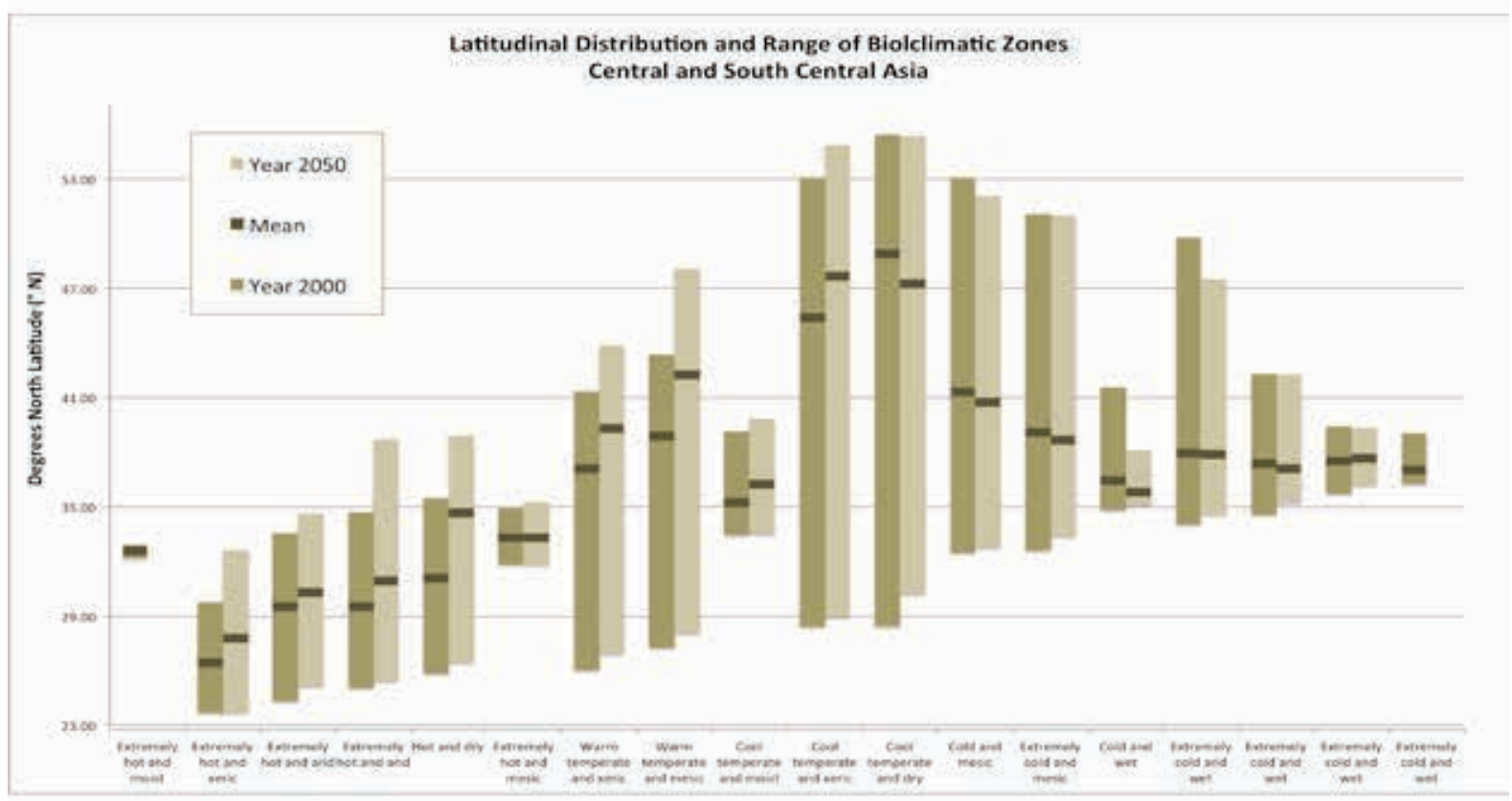

Table 3: Mean latitude of the CA_EnS bioclimatic zones under current (averaged 1960-2000) bioclimatic conditions (geographic degrees north latitude), and mean northward shift $(\mathrm{km})$ of the mean, minimum and maximum latitude, as averaged across all four RCP scenarios, by the year 2050 .

\begin{tabular}{|c|c|c|c|c|}
\hline \multirow[t]{2}{*}{ CA_EnS Zone } & \multirow{2}{*}{$\begin{array}{c}\text { Year } 2000 \\
\text { Mean Latitude }(\operatorname{deg} N)\end{array}$} & \multicolumn{3}{|c|}{ Year 2050 - Northward Shift (km) } \\
\hline & & Mean & Min & Max \\
\hline Extremely cold and wet & 37.029 & - & - & - \\
\hline Extremely cold and wet & 37.535 & 10 & 52 & $(2)$ \\
\hline Extremely cold and wet & 37.397 & (32) & 73 & $(1)$ \\
\hline Extremely cold and wet & 37.96 & (9) & 61 & $(254)$ \\
\hline Cold and wet & 36.412 & (67) & 33 & $(385)$ \\
\hline Extremely cold and mesic & 39.11 & $(51)$ & 89 & $(0)$ \\
\hline Cold and mesic & 41.31 & $(67)$ & 31 & $(116)$ \\
\hline Cool temperature and dry & 48.865 & $(178)$ & 199 & $(5)$ \\
\hline Cool temperature and xeric & 45.376 & 251 & 59 & 205 \\
\hline Cool temperature and moist & 35.217 & 112 & 7 & 84 \\
\hline Warm temperatate and mesic & 38.854 & 373 & 89 & 523 \\
\hline Warm temperatate and xeric & 37.066 & 247 & 100 & 285 \\
\hline Extremely hot and mesic & 33.266 & 1 & $(2)$ & 39 \\
\hline Hot and dry & 31.049 & 404 & 66 & 378 \\
\hline Extremely hot and arid & 29.508 & 159 & 45 & 448 \\
\hline Extremely hot and arid & 29.471 & 92 & 91 & 116 \\
\hline Extremely hot and xeric & 26.402 & 155 & 0 & 319 \\
\hline Extremely hot and moist & 32.565 & - & - & - \\
\hline & Average Northward Shift & 87 & 62 & 102 \\
\hline
\end{tabular}




\section{Summary and conclusions}

Understanding and planning for adaptation and mitigation of climate and environmental change is crucial to implementation of sustainable development and effective environmental and biological conservation in central and south-central Asia. Climate change is and has been on-going, and is already evident and widely observed across the region. Meteorological data series for central Asia have shown a steady increase of annual and winter temperatures since the beginning of the $20^{\text {th }}$ century. Generally in line with predictions by global climate change models, the frequency of droughts has been observed to increase over the last few last decades, highlighting the predicted increase in inter-annual, as well as intra-annual variability and frequency of extreme events.

Overall, the results of the spatial analysis based upon the CIMP5 Earth System Model projections indicate a fairly quick and drastic change in the spatial distribution of bioclimatic conditions across the central and south-central regions, and predict significant and increasing biophysical and biological perturbation for biodiversity, ecosystems, ecosystem services, and agricultural and pastoral production systems, in the near- to medium-term future under all scenarios. The magnitude of the predicted change indicated by our analysis points to a prolonged period of profound impacts on terrestrial ecosystems, and ecosystem services across central and south-central Asia. This perturbation is predicted to be fully under way by 2050 as a result of warming and climate disruption, and the shifting of bioclimatic conditions spatially, particularly in mountainous regions. This change will impact upon and have increasingly substantial and direct impacts on ecosystems, biodiversity, agricultural crops, pastoral systems, water resources, as well as human health and livelihoods, throughout this region as this century progresses. Likewise, effectiveness of conservation efforts will be affected, as ecological conditions across the region may change beyond limits conducive for the species currently found within narrow niches or designated protected areas, or allow for newly invasive species.

A major conclusion to be drawn from this report is the overriding necessity to recognize the now central role of a rapidly changing climate and environment across central and south-central Asia, and the need to incorporate, mainstream and plan for adaptation within almost all aspects of sustainable development and conservation planning, efforts and policy. Below we list some of the major findings of the analysis and this working paper.

\section{Major findings}

\section{Bioclimatic indicators}

- The two countries of south-central Asia, namely Afghanistan and Pakistan, and south-eastern portions of central Asia (namely Tajikistan) appear to be approaching novel sets of bioclimatic conditions more rapidly than the northern portions of the region. The estimated year of climate departure for the various countries of the greater central and south-central Asia region ranges from 2040 to 2086. This is slightly earlier than for the global average (Mora et al, 2013). Even under the best case scenario (RCP 4.5), the entire region will experience novel climatic conditions within a little more than 60 years, by 2086 at the latest.

- By the year 2050, mean annual temperatures for these seven countries are projected to increase by, on average across the four emission scenarios, from 2.4 to $3.2^{\circ} \mathrm{C}$. Kazakhstan shows the largest increase in temperature in the region, Pakistan the lowest (possibly due to the moderating influence of the ocean). For the region overall, the average mean annual temperature of $9.3^{\circ} \mathrm{C}$ is projected to rise on average $2.9^{\circ} \mathrm{C}$, with the range of projections across the RCPs ranging from $2.4^{\circ} \mathrm{C}$ to $3.5^{\circ} \mathrm{C}$.

- The central and south-central Asia regions are both quite arid, with a mere $261 \mathrm{~mm}$ of annual precipitation for the combined region as a whole. Tajikistan receives the most precipitation in the region $(560 \mathrm{~mm})$; Turkmenistan the least $(163 \mathrm{~mm})$. 
- Almost all countries of the region are projected to experience slight increases in precipitation, on average $26 \mathrm{~mm}$ by 2050, except for Afghanistan, which is projected to experience a $10 \mathrm{~mm}$ decrease. Kyrgyzstan will see the largest increase $(30 \mathrm{~mm})$, and Turkmenistan remains nearly the same with only a very slight increase $(3 \mathrm{~mm})$. However, overall confidence levels in the precipitation projections of the CIMP5 Earth System Models are still quite low, with the variability among models generally higher (i.e. of lower confidence levels) than for the temperature projections, which has a higher level of agreement among models.

- The averaged mean PET for the whole central and region of $1095 \mathrm{~mm}$ (1960-2000) increases by more than $8 \%$ to $1187 \mathrm{~mm}$ by 2050 , indicating potentially high water demand by both managed agricultural and pastoral systems, and natural (unmanaged or lesser managed) ecosystems. All seven countries within this region show a similar increase in PET, i.e. of approx. 8 - $9 \%$ or just less than $100 \mathrm{~mm}$ on average. These results seem to indicate that any benefit derived from increased precipitation will likely just compensate for the increase in PET (driven by increasing temperatures).

- The Aridity-Wetness Index (AWI) is a general indicator of bioclimatic and plant growth conditions. Turkmenistan has the lowest AWI in the region (0.12), indicating a very severely arid climate, along with Uzbekistan (0.17), while Kyrgyzstan (0.60) and Tajikistan (0.84) have the slightly more mesic climates in the region. All countries experience a decrease in AWI (indicating a more arid climate) by 2005 . Turkmenistan and Uzbekistan only decrease very slightly, however, Tajikistan decreases from 0.84 to 0.77 indicating a significant trend towards increasing aridity for the region in a relatively short period of time.

- A simple, spatially articulated soil-water balance approach, used to model in-situ hydrological status, indicated that Tajikistan has the highest in-situ excess water $(359 \mathrm{~mm})$ for the region, followed by Kyrgyzstan $(189 \mathrm{~mm})$, with Turkmenistan $(15 \mathrm{~mm})$ having the lowest and least favourable moisture conditions. For the region as the whole, the average is a quite low $60 \mathrm{~mm}$, with concentrations of higher values (more humid conditions) in the higher elevations. Very little change in this water balance indicated by 2050 , primarily as high temperatures are increasing PET, and consequently AET, and slightly moister projected conditions are compensating for this increase in vapour flow.

\section{Projected change in spatial distribution of bioclimatic conditions}

- Eighteen major bioclimatic zones were identified through this study as currently found within central and south-central Asia, ranging from Extremely Hot and Moist at low elevations in the south, to Extremely Cold and Wet zones at the higher elevations.

- Mean annual temperatures for bioclimatic zones are generally inversely correlated with their average elevation. However, the zonal distribution of bioclimatic conditions also reflects a strong influence of latitudinal temperature and moisture gradients.

- Bioclimatic zones found within the region are generally dry to mesic (with the exception of the small area of Extremely Hot and Moist zone found primarily in Pakistan), reflecting the low average precipitation across the region. This is likewise evident in the Aridity-Wetness Index, which indicates relatively dry to extremely dry conditions for all the zones except the highest elevation Cold and Wet to Extremely Cold and Wet zones.

- Cool Temperate zones stretched across the northern portions of central Asia, with relatively low average elevation, comprise more than half of the total combined region (58\%). Of the 18 zones, only 10 zones individually cover more than $1 \%$ of the total regional area, with the four most extensive zones (i.e. the Cool Temperate and the Warm Temperate) together comprising more than $76 \%$ of the total area.

- By the year 2050, substantial shifting and spatial displacement of the bioclimatic zones is seen across the region. Zones shift both upslope and northward. 
- The largest zone in areal extent (Cool Temperate and Xeric) increases substantially, by as much as $87,000 \mathrm{~km}^{2}$, as do both the Warm temperate zones which together increase by over $400,000 \mathrm{~km}^{2}$.

- The Cool Temperate and Dry zone decreases by almost half, or more than $640,000 \mathrm{~km}^{2}$. The very small area of Extremely Hot and Moist (just over $1500 \mathrm{~km}^{2}$ ) disappears completely by 2050 . The four Extremely Cold and Wet zones decrease by more 50\% in areal extent, and viewed along the temperature gradient, all the zones cooler than the Cool Temperate, including all the Cold and the Extremely Cold zones decrease in size.

- The average mean elevation of all the bioclimatic zones shifts upward by $220 \mathrm{~m}$. Not all zones shift upward, with three zones shifting their mean elevation downward (in conjunction with significant spatial displacement). Upward shifting of both the mean elevation, and the minimum and maximum elevations is more evident in the cool to colder zones, which are also the higher elevation zones found primarily in the mountainous regions, several of which shift in excess of 500 metres upward in mean elevation. Almost all of the zones shift upward substantially in their maximum elevational extent, and most also shift upward in their minimum elevational extent (or at least stay approximately at the same minimum elevation). The warmer zones all increase the extent of their elevational range substantially.

- A similar distribution is seen in the latitudinal range and mean latitude of the bioclimatic zones. The coldest and higher elevation zones, restricted to the mountain, do not show the latitudinal shift. However, most of the warmer and lower elevation zones show a pronounced northward shift in their mean latitudinal range, with an average $87 \mathrm{~km}$ northward migration (for all zones). Likewise there is a large shift in maximum northward latitude of $102 \mathrm{~km}$ on average. A few zones also show a southerly expansion of their range as well, however, the average southern limit of bioclimatic zone moves northward by $62 \mathrm{~km}$.

Impacts on specific ecosystems, ecosystem function, ecosystems services, vegetation types, wildlife, and/or agricultural and pastoral production systems, are difficult to predict, as the spatial distribution of life forms and ecosystems cannot be defined in purely eco-physiological terms, and are likewise subject to other secondary change processes, e.g. disruption of pest or pollinator cycles or invasive species. Although ecosystem and production ranges may shift, the ability to survive, adapt or benefit from these changes is system- and to a certain extent, site-specific, and depends on many factors as to the degree of vulnerability, not the least of which is the socio-ecological resilience of that system, and along with its socio-economic capacity for adaptation. Better understanding these responses is among the efforts that must be implemented if sustainable development and adaptation strategies and policies are to be effective within the context of a rapidly changing climate. The results of this analysis forewarn of a prolonged period of climate perturbation and ecological disruption and potentially widespread extinctions, without concerted conservation efforts to mitigate habitat loss.

Based on improved knowledge of projected changes, impacts and responses, and science- and evidence-based decision making and planning, a number of actions (and tools) are available to incorporate and mainstream climate change and adaption into policy and decision-making at various scales and levels. A number of authors have reviewed recommendations for adaptation strategies (Mawdsley et al, 2009), biodiversity management in the face of climate change (Heller and Zavaleta, 2009), and incorporating climate change into systematic conservation planning (Groves et al, 2012). All stress the need to incorporate a fundamental awareness of on-going rapid climatic change in all levels of sustainable development and conservation planning and policy. In response to anticipated effects of climate change, development and conservation organizations and government agencies throughout the world are developing "adaptation strategies" at various scales to facilitate the adjustment of human society and ecological systems to altered climate regimes. 


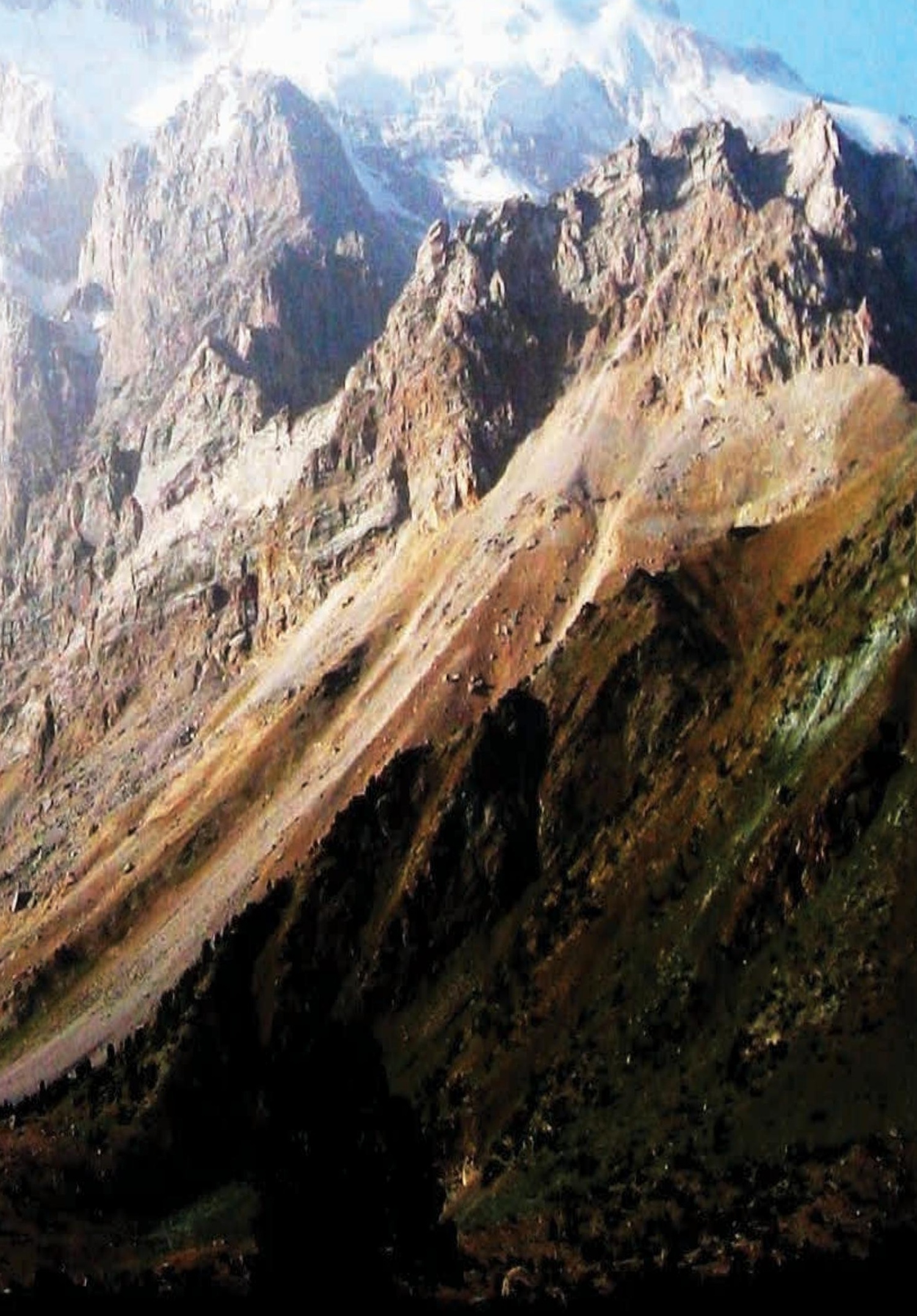




\section{Appendix 1}

\section{In-situ water balance model}

A spatially distributed Thornthwaite-Mather water balance modelling approach (Thornthwaite 1948; Thornthwaite and Mather 1955) has been used to examine hydrological differences in actual evapotranspiration, soil water content and runoff. This model uses the average spatially distributed values of monthly precipitation and monthly potential evapotranspiration (PET), land use classes, soil depth and soil water holding capacity, and returns monthly spatially-distributed raster data representing actual evapotranspiration (AET), surface runoff (R) and soil water content (SWC). All the results are computed on a monthly basis throughout a year for current climate and future projected scenarios, and the results are aggregated into yearly figures.

A soil water balance budget is computed as height of water in $\mathrm{mm}$ for each month $(\mathrm{m})$, as:

$$
\Delta S W C_{m}=E \operatorname{Prec}_{\mathrm{m}}-A E T_{m}-R_{m} \mathrm{~mm} / \mathrm{month}
$$

where:

$\triangle S W C_{m}$ is the change in soil water content, $E \operatorname{Prec}_{\mathrm{m}}$ is the effective precipitation, $A E T_{m}$ is the actual evapotranspiration, and $R_{m}$ is the runoff component, which includes both surface runoff and subsurface drainage. SWC can never exceed a maximum value, $S W C_{\max }$, which is the total $S W C$ available for evapotranspiration (ET).

Therefore, the SWC at the end of the month, is equal to:

Where:

$$
S W C_{m}^{f}=\left\{\begin{array}{clc}
S W C_{\max } & \text { if } & S W C_{m}^{f} \leq S W C_{\max } \\
S W C_{m}^{b}+E \operatorname{Pr} e c_{m}-A E T_{m}-R_{m} & \text { if } & S W C_{m}^{f}>S W C_{\max }
\end{array}\right.
$$

$S W C_{m}^{b}$ is the soil water content at the beginning of the month. The SWC at the end of the month, $S W C_{m}^{f}$, is set as the SWC at the beginning of the following month, $S W C_{m+1}^{b}$. All the water exceeding $S W C_{\max }$ is accounted as runoff:

$$
R_{m}=\left\{\begin{array}{ccc}
S W C_{m}^{b}+E^{2} \operatorname{prec}_{m}-A E T_{m}-S W C_{\max } & \text { if } & S W C_{m}^{b}+\text { Eprec }_{m}-A E T_{m}>S W C_{\max } \\
0 & \text { if } S W C_{m}^{b}+E \text { Frec }_{m}-A E T_{m} \leq S W C_{\max }
\end{array}\right.
$$

Method of calculation for the component terms in these formulas are explained in the following sections.

\section{Monthly Potential Evapotranspiration (PET)}

Potential evapotranspiration (PET) is estimated on a regional scale to calculate the Aridity Index (AI). PET is a measure of the ability of the atmosphere to remove water through ET processes. The FAO introduced a definition of PET as the ET of a reference crop in optimal conditions having the following characteristics: well watered grass with an assumed height of $12 \mathrm{~cm}$, a fixed surface resistance of $70 \mathrm{~s} / \mathrm{m}$ and an albedo of 0.23 (Allen et al, 1998). Five different methods of calculating PET were tested to determine which equation performed the best for the objectives of this analysis: Thornthwaite (Thornthwaite, 1948), Thornthwaite modified by Holland (Holland, 1978), Hargreaves (Hargreaves et al, 1985), Hargreaves modified by Droogers (Droogers and Allen, 2002), and the FAO 
Penman-Monteith global dataset (Allen et al, 1998) at $20 \mathrm{~km}$ resolution (available online). Values for PET calculated using each of the above five methods were compared to PET values for specific climate stations calculated using climate station data $(\mathrm{n}=2288)$. These PET values are calculated using the more complex Penman-Monteith model applied to direct observations of the various climatic parameters, and were obtained from the FAOCLIM climate station dataset (Allen et al, 1998), available online from FAO. Based on the results of the comparative validation, the Hargreaves model was chosen to model PET globally for this study. This method performed almost as well as the FAO Penman-Monteith method, but required less parameterization, and had significantly lower sensitivity to error in climatic inputs (Hargreaves and Allen, 2003). This allowed for its application at a finer resolution (at $1 \mathrm{~km}$; resolution of the FAO Penman-Monteith dataset is $20 \mathrm{~km}$ ). Hargreaves (1994) uses mean monthly temperature (Tmean), mean monthly temperature range (TD) and extraterrestrial radiation (RA, radiation on top of atmosphere) to calculate PET, as shown below:

$$
\mathrm{PET}=0.0023 \cdot \mathrm{RA} \cdot(\text { Tmean }+17.8) \cdot \mathrm{TD} 0.5 \quad(\mathrm{~mm} / \mathrm{d})
$$

\section{Actual Evapotranspiration and Green Water Vapour Flows}

Actual evapotranspiration (AET) is the quantity of water that is removed from the soil due to evaporation and transpiration processes (Maidment, 1992). AET is dependent on vegetation characteristics, quantity of water available in the soil and soil hydrological properties (mainly soil water retention curves) (Allen et al, 1998):

$$
A E T_{m}=K_{\text {veg }} * P E T_{m} \mathrm{~mm} / \mathrm{month}
$$

where:

$$
\begin{aligned}
& K_{\text {soil }}=\text { reduction factor dependent on volumetric soil moisture content (0-1); and } \\
& K_{\text {veg }}=\text { vegetation coefficient dependent on vegetation characteristics (0.3-1.3). }
\end{aligned}
$$

The vegetation coefficient $\left(\mathrm{K}_{\text {veg }}\right)$ is used to calibrate the reference PET for different crops or vegetation types. $\mathrm{K}_{\text {veg }}$ values for the various land use types were modelled by combining $\mathrm{K}_{\text {veg }}$ coefficients for vegetation types taken from the literature, and their estimated occurrence within each land use type. $\mathrm{K}_{\mathrm{veg}}$ values are available from literature for agronomic crops (Allen et al, 1998) and for other vegetation types from various sources (Allen et al, 1998; Costello and Jones 2000; U. S. Bureau of Reclamation 2005).

The maximum amount of soil water available for ET processes within the plant rooting depth zone, here defined as $\mathrm{SWC}_{\max }$, is equal to the $\mathrm{SWC}$ at field capacity $\left(\mathrm{SWC}_{\mathrm{fc}}\right)$ minus the $\mathrm{SWC}$ at wilting point $\left(\mathrm{SWC}_{\mathrm{wp}}\right)$ times the rooting depth.

$$
S W C_{\max }=R D^{*}\left(S W C_{f_{c}}-S W C_{w p}\right)
$$

where:

$$
\begin{aligned}
& S W C_{\max }=\text { maximum soil water content available for ET }(\mathrm{mm}) ; \\
& R D=\text { rooting depth }(\mathrm{mm}) ; \\
& S W C_{w p}=\text { soil water content at wilting point }(\mathrm{mm} / \mathrm{mm}) ; \text { and } \\
& S W C_{f c}=\text { soil water content at field capacity }(\mathrm{mm} / \mathrm{mm}) .
\end{aligned}
$$

Soil water content at field capacity and wilting point are available from literature for the various soil texture typologies (Jensen et al, 1990). Rooting depth values for the various land use types were 
modelled by combining the rooting depth of six specific vegetation classes, namely Trees, Shrubs, Pasture, Grass, Crop and Bare Land, under non-water stress conditions, based upon their estimated occurrence within specific land use types. Rooting depth of vegetation is likely to be deeper under water stressed conditions, as water is stored more at depth in the soil during dry seasons. Rooting depths values for vegetation types under non-water stress conditions are available from the literature (Allen et al, 1998). A global dataset of ecosystem rooting depth (Schenk and Jackson, 2002) was used to scale rooting depth of the various vegetation types to more realistic water stressed conditions.

The soil stress coefficient (Ksoil) represents the ET reduction factor resulting from the limit imposed by the absolute volumetric soil water content. The model uses a simple linear soil moisture stress function that is considered appropriate for monthly computation (Dyck 1983):

$$
K_{\text {sail }}=S W C_{m} / S W C_{\max }
$$

$S W C_{m}=$ soil water content averaged over the month

\section{Effective precipitation}

Effective precipitation (EPrec), that part of precipitation that adds water to the soil, is calculated as the gross precipitation (GPrec) minus the precipitation intercepted by canopy cover and litter (Int). The quantity of rain intercepted is proportional to the interception coefficient Kint, specific for different types of land use, calculated as a fraction of GPrec. Rain interception is the process by which precipitation is intercepted by the vegetation canopy (canopy interception losses) and litter (litter interception losses), where it is subject to evaporation. Interception (Int) has an important role in the water budget, as it reduces the amount of precipitation available for SWC. The losses due to interception depend on vegetation type, vegetation cover and the intensity, duration, frequency and form of precipitation (Dingman, 1993). Observations derived from several experiments demonstrate that vegetation interception is a mechanical function of the storage space of vegetation structure (Wilm, 1957). Forests with dense crowns and large leaf areas have higher interception losses (IPCC, 2000), cloud forests being the exception. Interception losses are greater for evergreen forest compared to seasonally leaf-shedding (Schulze, 1982; Tate, 1996) and for fast-growing trees compared to slow-growing trees (IPCC 2000). Thin or sparse vegetation shows low values of interception (Wilm, 1957). Interception values for the various land use types were modelled by combining interception coefficients, widely available in the literature for the six vegetation classes, namely Tree, Shrubs, Pasture, Grass, Crop and Bare Land (Hamilton and Rowe, 1949; Young et al, 1984; Thurow et al, 1987; Farrington and Bartle, 1991; Calder, 1992; Tate, 1996; Le Maitre et al, 1999; Schroth et al, 1999), with the estimated occurrence of that vegetation class within a land use type.

For each month $E \operatorname{Prec}_{m}$ is calculated as:

$$
E \operatorname{Prec}_{m}=G \text { Prec }- \text { Int }
$$

where: Int is equal to:

$$
\text { Int }=\left(G \operatorname{Prec} * \mathrm{~K}_{\text {int }}\right)
$$

Therefore:

$$
\text { Prec }_{m}=G \operatorname{Prec}-\left(G \operatorname{Prec}^{*} \mathrm{~K}_{\text {int }}\right) G \operatorname{Prec} *\left(1-\mathrm{K}_{\text {int }}\right)
$$

The AET and Int components of the model are combined to quantify 'green water' vapour flows, i.e., that portion of precipitation that evaporates into the atmosphere, and is not available as runoff (or 'excess in-situ water'). 


\section{Appendix 2}

CIMP5 Earth System Models (ESM), downscaled to $\sim 1 \mathrm{~km}^{2}$ resolution, across four representative conservation pathways (RCP), representing a range of emission scenarios from lowest (RCP 2.6) to highest (RCP 8.5).

Results from sixty-three ESM/RCP combinations were used in the analysis.

\begin{tabular}{|c|c|c|c|c|c|c|c|c|c|c|c|c|c|c|c|c|c|c|c|}
\hline $\begin{array}{l}\infty \\
\infty \\
0 \\
0 \\
0 \\
\alpha\end{array}$ & $x$ & $x$ & $x$ & & $x$ & $x$ & & $x$ & $\times$ & $\times$ & $\times$ & $x$ & $x$ & $\times$ & $x$ & $x$ & $x$ & $x$ & $x$ \\
\hline 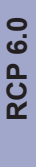 & & $\times$ & $x$ & & & & $\times$ & $\times$ & $\times$ & & $\times$ & & $\times$ & $x$ & $x$ & $\times$ & & $\times$ & $x$ \\
\hline 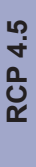 & $\times$ & $x$ & $x$ & $\times$ & $x$ & $\times$ & $x$ & $\times$ & $\times$ & $\times$ & $\times$ & $\times$ & $\times$ & $x$ & $x$ & $\times$ & $\times$ & $\times$ & $\times$ \\
\hline 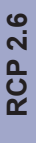 & & $x$ & $\times$ & & $x$ & $\times$ & $\times$ & $x$ & $\times$ & & $\times$ & & $\times$ & $\times$ & $x$ & $\times$ & $\times$ & $\times$ & $x$ \\
\hline 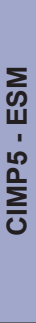 & $\begin{array}{l}\stackrel{0}{1} \\
\stackrel{u}{u} \\
\underset{\cup}{U}\end{array}$ & 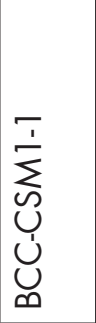 & $\sum_{U}^{J}$ & 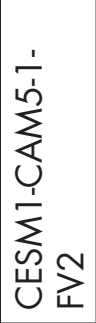 & 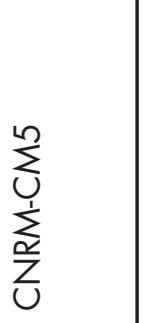 & 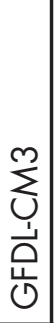 & 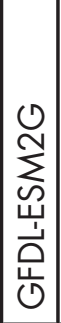 & $\begin{array}{l}\stackrel{\alpha}{\dot{N}} \\
\stackrel{y}{\dot{\nu}} \\
\frac{\mathscr{N}}{0}\end{array}$ & 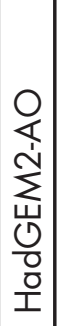 & 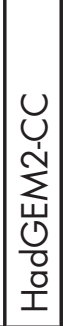 & 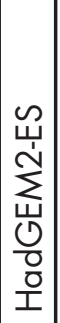 & $\frac{\sum_{u}^{\searrow}}{\sum_{z}^{J}}$ & 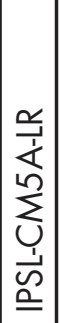 & 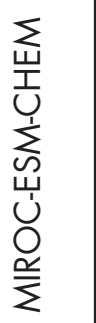 & 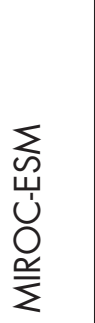 & $\begin{array}{l}\text { Un } \\
\bigcirc \\
\underline{y}\end{array}$ & 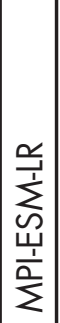 & $\begin{array}{l}\sum_{u}^{m} \\
0 \\
u \\
\frac{1}{\alpha} \\
\frac{\alpha}{\Sigma}\end{array}$ & 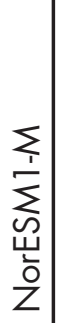 \\
\hline 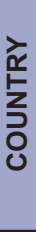 & $\frac{\frac{\sigma}{0}}{\frac{0}{5}}$ & 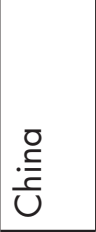 & 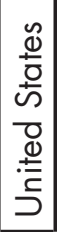 & 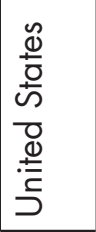 & 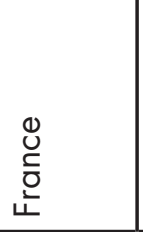 & 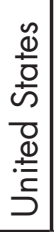 & 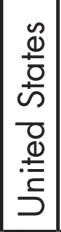 & 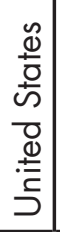 & 当 & 兰 & 弚 & $\begin{array}{l}\frac{\sigma}{N} \\
\stackrel{\sim}{\alpha}\end{array}$ & 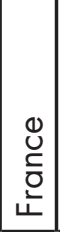 & $\begin{array}{l}\frac{}{0} \\
\text { o } \\
\text { 뭉 }\end{array}$ & 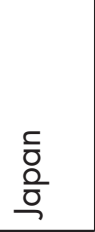 & $\begin{array}{l}\text { 듬 } \\
\text { 음 }\end{array}$ & 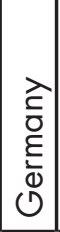 & $\begin{array}{l}\text { 흐 } \\
\text { 음 } \\
\end{array}$ & $\begin{array}{l}\text { ते } \\
\text { zo } \\
\text { Z }\end{array}$ \\
\hline 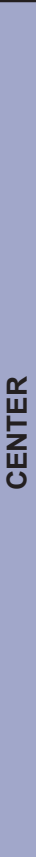 & 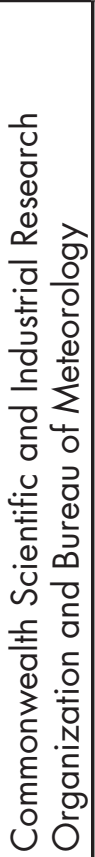 & 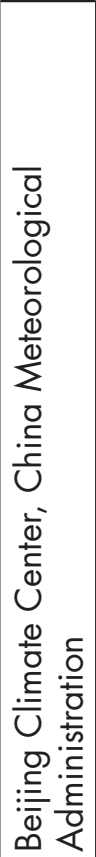 & 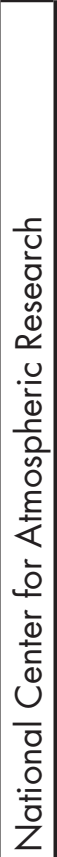 & 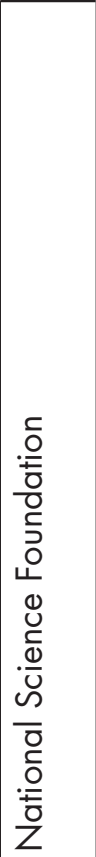 & 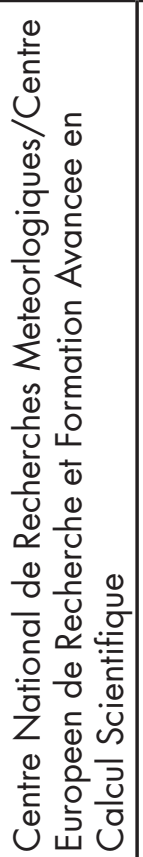 & 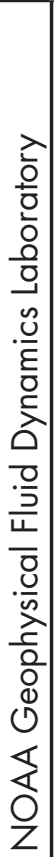 & 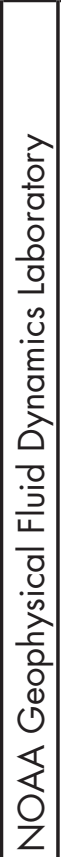 & 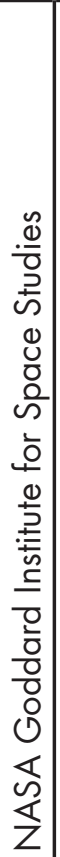 & 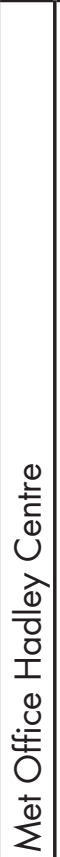 & 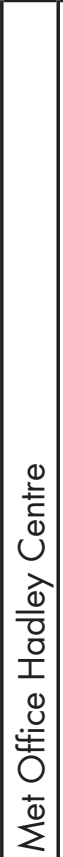 & 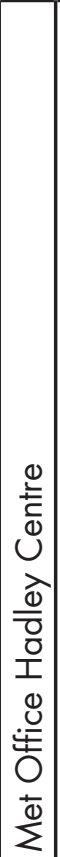 & 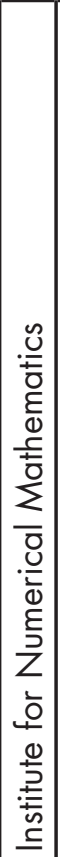 & 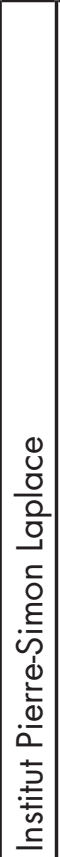 & 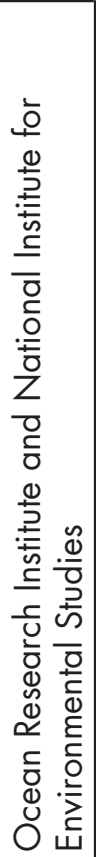 & 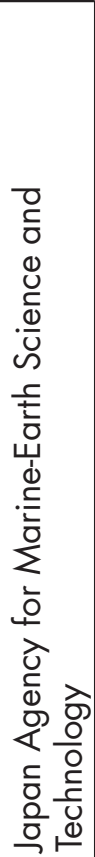 & 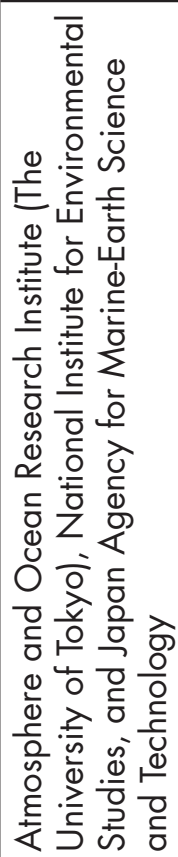 & 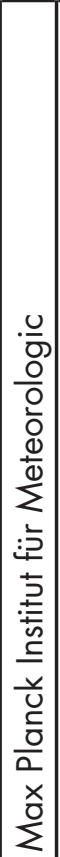 & 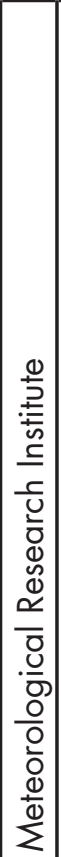 & 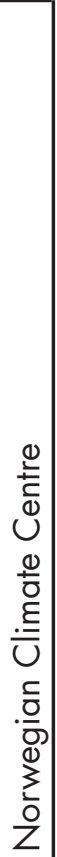 \\
\hline
\end{tabular}




\section{References}

Alibekov, L. A. 2000. Mountain deforestation in Middle Asia and agroforest ameliorations. Oecologia Montana. 9: 44-47.

Allen, R. G.; Pereira, L. S.; Raes, D.; Smith, M. 1998. Crop evapotranspiration - Guidelines for computing crop water requirements. FAO Irrigation and Drainage Paper 56. Rome: FAO (Food and Agriculture Organization of the United Nations).

Bobojonov, I., Aw-Hassan, A., 2014. Impacts of climate change on farm income security in central Asia: An integrated modeling approach. Agriculture, Ecosystems \& Environment 188: 245-255.

Calder, I. R. 1992. Water use in eucalypts - a review. Growth and Water Use of Forest Plantations. I. R. Calder, R. L. Hall and P. G. Adlard. New York, J. Wiley: 167-179.

Conrad, C., Schorcht, G., Tischbein, B., Davletov, S., Sultonov, M., Lamers, J.P.A., 2012. AgroMeteorological Trends of Recent Climate Development in Khorezm and Implications for Crop Production, in: Martius, C., Rudenko, I., Lamers, J.P.A., Vlek, P.L.G. (Eds.), Cotton, Water, Salts and Soums. Springer Netherlands, Dordrecht, pp. 25-36. doi:10.1007/978-94-007-1963-7_2

Costello, L. R.; and Jones, K. S. 2000. Water Use Classification of Landscape Species (WUCOLS III). A Guide to Estimating Irrigation Water Needs of Landscape Plantings in California. Sacramento, California Department of Water Resources.

Dingman, S. L. 1993. Physical Hydrology. Prentice Hall. New Jersey, USA.

Droogers, P.; and Allen, R. G. 2002. Estimating reference evapotranspiration under inaccurate data conditions. Irrigation and Drainage Systems, 16(1): 33-45.

Dukhovny, V.A., Ziganshina, D., 2011. Ways to improve water governance. Irrigation and Drainage $60,569-578$.

Dyck, S. 1983. Overview on the present status of the concepts of water balance models. IAHS Publ. 148. Wallingford: 3-19.

Farrington, P.; and Bartle, G. A. 1991. Recharge beneath a Banksia woodland and a Pinus pinaster plantation on coastal deep sands in south Western Australia. Forest Ecology and Management 40: 101-118.

Fischer, G., Tubiello, F.N., van Velthuizen, H., Wiberg, D.A., 2007. Climate change impacts on irrigation water requirements: Effects of mitigation, 1990-2080. Technological Forecasting and Social Change 74, 1083-1107.

Groves, C.R., Game, E.T., Anderson, M.G., Cross, M., Enquist, C., Ferdaña, Z., Girvetz, E., Gondor, A., Hall, K.R., Higgins, J., Marshall, R., Popper, K., Schill, S., Shafer, S.L., 2012. Incorporating climate change into systematic conservation planning. Biodivers Conserv 21, 1651-1671. doi:10.1007/s10531-012-0269-3

Hamilton, E.L.; and Rowe, P. B. 1949. Rainfall interception by chaparral in California. Division of Forestry, Sacramento, Calif.

Hargreaves, G. H. 1994. Defining and using reference evapotranspiration. Journal of Irrigation and Drainage Engineering, ASCE, 120(6): 1132-1139.

Hargreaves, G. H.; and Allen, R. G. 2003. History and evaluation of Hargreaves evapotranspiration Equation. Journal of Irrigation and Drainage Engineering. ASCE, 129(1): 53-63.

Hargreaves, G. L.; Hargreaves, G. H.; Riley, J. P. 1985. Irrigation Water Requirements for Senegal River Basin. Journal of Irrigation and Drainage Engineering, ASCE, 111(3): 265-275.

Heller, N.E., Zavaleta, E.S., 2009. Biodiversity management in the face of climate change: A review of 22 years of recommendations. Biological Conservation 142, 14-32. doi:10.1016/j. biocon.2008.10.006 
Hijmans, R.J., Cameron, S.E., Parra, J.L., Jones, P.G., Jarvis, A., 2005. Very high resolution interpolated climate surfaces for global land areas. Int. J. Climatol. 25, 1965-1978.

Holdridge L.R. 1947 Determination of World Plant Formations From Simple Climatic Data. Science 105:367-368

Holland, H. D. 1978. The Chemistry of the Atmosphere and Oceans. New York, Wiley.

IPCC (Intergovernmental Panel on Climate Change). 2000. IPCC Special Report on Land Use, Land-Use Change and Forestry. A special report of the Intergovernmental Panel on Climate Change. Approved at IPCC Plenary XVI (Montreal, 1-8 May, 2000). IPCC Secretariat, c/o World Meteorological Organization, Geneva, Switzerland. At http://www.ipcc.ch/.

IPCC, 2013: Summary for Policymakers. In: Climate Change 2013: The Physical Science Basis. Contribution of Working Group I to the Fifth Assessment Report of the Intergovernmental Panel on Climate Change [Stocker, T.F., D. Qin, G.-K. Plattner, M. Tignor, S.K. Allen, J. Boschung, A. Nauels, Y. Xia, V. Bex and P.M. Midgley (eds.)]. Cambridge University Press, Cambridge, United Kingdom and New York, NY, USA.

Le Maitre, D. C.; Scott, D. F.; Colvin, C. 1999. A review of information on interactions between vegetation and groundwater. Water SA 25(2): 137-152.

Lioubimtseva, E., 2007. Possible changes in the carbon budget of arid and semi-arid Central Asia inferred from landuse/landcover analyses during 1981 to 2001, in: Lal, R., Suleimenov, M., Doraiswamy, P., Hansen, D.O., Stewart, B.A. (Eds.), Climate Change and Terrestrial Carbon Sequestration in Central Asia. ... change and terrestrial carbon sequestration in ..., pp. 441-451.

Lioubimtseva, E., Cole, R., Adams, J.M., Kapustin, G., 2005. Impacts of climate and land-cover changes in arid lands of Central Asia. Journal of Arid Environments 62, 285-308. doi:10.1016/j. jaridenv.2004.11.005

Lioubimtseva, E., Henebry, G.M., 2009. Climate and environmental change in arid Central Asia: Impacts, vulnerability, and adaptations. Journal of Arid Environments 73, 963-977. doi:10.1016/j. jaridenv.2009.04.022

Maidment, D. R. 1992. Handbook of hydrology. New York, McGraw-Hill.

Markov, K.V., 1951. Is Middle and Central Asia getting drier? Voprosi geogragii (Geographic questions). Geografgiz 98-116.

Mawdsley, J.R., O’Malley, R., Ojima, D.S., 2009. A Review of Climate Change Adaptation Strategies for Wildlife Management and Biodiversity Conservation. Conservation Biology 23, 1080-1089. doi:10.1111/j.1523-1739.2009.01264.x

Meehl, G.A., Bony, S., 2011. Introduction to CMIP5. Clivar Exchanges 16, 2-5.

Metzger M, Bunce R. 2005. A climatic stratification of the environment of Europe. Global Ecology and Biogeography. 14:549-563.

Metzger, M.J., Brus, D.J., Bunce, R., Carey, P.D., Goncalves, J., Honrado, J.P., Jongman, R., Trabucco, A., Zomer, R., 2013b. Environmental stratifications as the basis for national, European and global ecological monitoring. Ecological Indicators 26-35.

Metzger, M.J., Bunce, R.G.H., Jongman, R.H.G., Sayre, R., Trabucco, A., Zomer, R., 2013a. A highresolution bioclimate map of the world: a unifying framework for global biodiversity research and monitoring. Global Ecology and Biogeography 22, 630-638.

Mora, C., Frazier, A.G., Longman, R.J., Dacks, R.S., Walton, M.M., Tong, E.J., Sanchez, J.J., Kaiser, L.R., Stender, Y.O., Anderson, J.M., Ambrosino, C.M., Fernandez-Silva, I., Giuseffi, L.M., Giambelluca, T.W., 2013. The projected timing of climate departure from recent variability. Nature 502, 183-187. 
Peel MC, Finlayson BL, Mcmahon TA (2007) Updated world map of the Köppen-Geiger climate classification.

Perelet, R. 2007. Central Asia: Background Paper on Climate Change. Fighting Climate Change: Human Solidarity in a Divided World. Human Development Report 2007/2008. Human Development Report Office Occasional Paper. UNDP.

Pilifosova, O.V., Eserkepova, I.B., Dolgih, S.A., 1997. Regional Climate Change Scenarios Under Global Warming In Kazakhstan. Climatic Change 36, 23-40. doi:10.1023/A:1005368404482

Ramirez-Villegas, J., Jarvis, A., 2010. Downscaling global circulation model outputs: the delta method decision and policy analysis. International Center for Tropical Agriculture, CIAT, Cali, Colombia.

Sayre, R., J. Dangermond, C. Frye, R. Vaughan, P. Aniello, S. Breyer, D. Cribbs, D. Hopkins, R. Nauman, W. Derrenbacher, D. Wright, C. Brown, C. Convis, J. Smith, L. Benson, D. Paco VanSistine, H. Warner, J. Cress, J. Danielson, S. Hamann, T. Cecere, A. Reddy, D. Burton, A. Grosse, D. True, M. Metzger, J. Hartmann, N. Moosdorf, H. Dürr, M. Paganini, P. DeFourny, O. Arino, S. Maynard, M. Anderson, and P. Comer. 2014. A New Map of Global Ecological Land Units - An Ecophysiographic Stratification Approach. Washington, DC: Association of American Geographers. 46 pages.

Schroth, G.; da Silva, L. F.; Wolf, M. A.; Teixeira, W. G.; Zech, W. 1999. Distribution of throughfall and stemflow in multi-strata agroforestry, perennial monoculture, fallow and primary forest in central Amazonia, Brazil. Hydrological Processes 13: 1423-1436.

Schulze, E. D. 1982. Plant life forms and their carbon, water and nutrient relations. Physiological Plant Ecology II. Water Relations and Carbon Assimilation. O. L. Lange; C. B. Osmond; and V. Ziegler. Berlin, Germany, Springer-Verlag. 615-676.

Tate, K. W. 1996. Interception on Rangeland Watersheds - Factsheet No. 36. U. C. Cooperative Extension and USDA Natural Resources Conservation Service, Rangeland Watershed Program.

Tate, K. W. 1996. Interception on Rangeland Watersheds - Factsheet No. 36. U. C. Cooperative Extension and USDA Natural Resources Conservation Service, Rangeland Watershed Program.

Thornthwaite, C. 1948. An approach toward a rational classification of climate. Geographic Review 38:55-94

Thornthwaite, C.; and Mather, J. 1955. The water balance. Pub Climatol, 8(1): 1-104.

Thurow, T. L.; Blackburn, W. H.; Taylor, C. A. 1987. Rainfall interception by midgrass, shortgrass and live oak mottes. Journal of Range Management 40: 455-460.

Trabucco, A., Zomer, R.J., Bossio, D.A., van Straaten, O., Verchot, L.V., 2008. Climate change mitigation through afforestation/reforestation: A global analysis of hydrologic impacts with four case studies. Agriculture Ecosystems and Environment 126, 81-97. doi:10.1016/j. agee.2008.01.015

U.S. Bureau of Reclamation. 2005. Agrimet Data System.

Vuuren, D.P., Edmonds, J., Kainuma, M., Riahi, K., Thomson, A., Hibbard, K., Hurtt, G.C., Kram, T., Krey, V., Lamarque, J.-F., Masui, T., Meinshausen, M., Nakicenovic, N., Smith, S.J., Rose, S.K., 2011. The representative concentration pathways: an overview. Climatic Change 109, 5-31. doi:10.1007/s10584-011-0148-z

Wilm, H. G. 1957. The influence of forest vegetation on water and soil. Unasylva, 11(4).

Young, J. A.; R. A. Evans, R.A.; Easi, D. A. 1984. Stemflow on western juniper (Juniprus occidentalis) trees. Weed Sci. 32: 320-327.

Zomer, R., Trabucco, A., Van Straaten, O., Bossio, D., 2006. Carbon, land and water: A global analysis of the hydrologic dimensions of climate change mitigation through afforestation/ reforestation 101 . 
Zomer, R.J., Bossio, D.A., Trabucco, A., Yuanjie, L., Gupta, D.C., Singh, V.P., 2007. Trees and water: smallholder agroforestry on irrigated lands in Northern India 122.

Zomer, R.J., Trabucco, A., Bossio, D., Verchot, L.V., 2008. Climate change mitigation: A spatial analysis of global land suitability for clean development mechanism afforestation and reforestation. Agriculture Ecosystems and Environment 126: 67-80.

Zomer, R.J., Trabucco, A., Metzger, M., Oli, K.P., 2013. Environmental Stratification of Kailash Sacred Landscape and Projected Climate Change Impacts on Ecosystems and Productivity: ICIMOD Working Paper 2013/1. International Centre for Integrated Mountain Development (ICIMOD), Kathmandu, Nepal.

Zomer, R.J., Trabucco, A., Wang, M., Lang, R., Chen, H., Metzger, M.J., Smajgl, A., Beckschäfer, P., Xu, J., 2014. Environmental stratification to model climate change impacts on biodiversity and rubber production in Xishuangbanna, Yunnan, China. Biological Conservation 170, 264-273. 

The World Agroforestry Centre is an autonomous, non-profit research organization whose vision is a rural transformation in the developing world as smallholder households increase their use of trees in agricultural landscapes to improve food security, nutrition, income, health, shelter, social cohesion, energy resources and environmental sustainability. The Centre generates science-based knowledge about the diverse roles that trees play in agricultural landscapes, and uses its research to advance policies and practices, and their implementation that benefit the poor and the environment. It aims to ensure that all this is achieved by enhancing the quality of its science work, increasing operational efficiency, building and maintaining strong partnerships, accelerating the use and impact of its research, and promoting greater cohesion, interdependence and alignment within the organization.

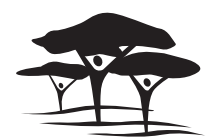

United Nations Avenue, Gigiri • PO Box 30677 • Nairobi, 00100 - Kenya Telephone: +254207224000 or via USA +1 6508336645 Fax: +254207224001 or via USA +1 6508336646

Email: worldagroforestry@cgiar.org•www.worldagroforestry.org

East and Central Asia Regional Programme \% Kunming Institute of Botany • 3/F North Research Building Heilongtan • 650201 Kunming • Yunnan Province • P.R. China Telephone: +86-871-6522-3014 • Fax: +86-871-6522-3377

Email: s.vandemoortel@cgiar.org • www.worldagroforestry.org/eca 